Running head: A Broad Internalizing Dimension Accounts for the Genetic Associations between Personality and Individual Internalizing Disorders

\title{
A Broad Internalizing Dimension Accounts for the Genetic Associations between Personality and Individual Internalizing Disorders
}

\author{
Holly E. Poore ${ }^{1}$, Ashley L. Watts ${ }^{2}$, Hannah P. Friedman ${ }^{3}$, Irwin D. Waldman ${ }^{4}$ \\ ${ }^{1}$ Department of Psychology, Virginia Commonwealth University \\ ${ }^{2}$ Department of Psychological Sciences, University of Missouri \\ ${ }^{3}$ Department of Psychology, University of Mississippi \\ ${ }^{4}$ Department of Psychology, Emory University
}

\begin{abstract}
Author Note
Correspondence should be addressed to Holly E. Poore, 8 N. Harrison St, Richmond, VA, 23220. email: poorehe@vcu.edu.

We have no conflicts of interest to disclose.

Funding Sources: ALW is funded through K99AA028306 (Principal Investigator: Watts).
\end{abstract}




\begin{abstract}
Much research has demonstrated that psychopathology can be described in terms of broad dimensions, representing liability for multiple psychiatric disorders. Broad spectra of psychopathology (e.g., internalizing and externalizing) are increasingly used as targets for research investigating the development, etiology, and course of psychopathology because they account for patterns of relatedness among disorders that were once presumed distinct. Thus, these spectra represent alluring targets for such study due to their comprehensive and parsimonious nature. Nevertheless, little research has established the role of individual disorders over and above broad dimensions in the study of psychopathology. In the current study, we investigate whether there are unique etiological associations between individual internalizing disorders and personality traits after accounting for their etiological associations with a broad internalizing dimension. We used a representative sample of twins $\left(\mathrm{N}_{\text {pairs }}=448\right)$ ages $4-19$ to examine the etiological associations between internalizing psychopathology and Big 5 personality dimensions. Internalizing was positively genetically associated with neuroticism and negatively genetically associated with extraversion, agreeableness, and conscientiousness. Moreover, internalizing accounted for most of the genetic variance shared between individual internalizing disorders and personality traits. Nevertheless, there were unique genetic associations between the following pairs of personality traits and disorders: neuroticism and social anxiety, extraversion and social anxiety, agreeableness and depression, and conscientiousness and compulsions. There was little evidence of environmental influences shared between internalizing and personality. In sum, a broad internalizing dimension adequately accounts for almost all of the etiological covariation between internalizing and personality, with several interesting exceptions.
\end{abstract}


Keywords: dimensions of psychopathology, quantitative genetic models, personalitypsychopathology associations 


\section{General Scientific Summary}

This study suggests that a broad internalizing dimension, which represents liability to experience a variety of mood and anxiety disorders, accounts for the genetic and environmental influences shared between personality traits and internalizing disorders. This finding supports the use of broad, transdiagnostic dimensions of psychopathology as targets in the study of the etiology, course, and treatment of psychopathology. 


\section{A Broad Internalizing Dimension Accounts for the Genetic Associations between Personality and Individual Internalizing Disorders}

Psychopathology is increasingly recognized as dimensional and hierarchically organized, with individual disorders subsumed by broad dimensions that explain much of their covariation, and which potentially reflect liability to multiple related disorders (Kotov et al., 2017).

Commonly identified spectra of psychopathology include internalizing, which comprises mood, anxiety, and fear-related symptoms, and externalizing, which comprises behavioral disinhibition and antagonism (Achenbach, 1966; Forbes et al., 2021; Krueger, 1999). The internalizing spectrum can be further decomposed into dimensions related to distress (e.g., depression, generalized anxiety) and fears (e.g., phobias, panic; Eaton et al., 2011; Greene \& Eaton, 2017; Krueger \& Markon, 2006), though these are highly overlapping in children (Watts et al., 2019a). These broad spectra represent alluring targets for study as they capitalize on the variance shared among multiple disorders, previously presumed to be distinct, and allow us to draw conclusions about a wider range of pathology. Accordingly, these spectra have recently been used as targets for studying the developmental (Marceau et al., 2015), genetic (Dick et al., 2008; Krueger et al., 2002; Kuo et al., 2021; Linnér et al., 2020), and environmental (Grabow et al., 2017; Marceau \& Neiderhiser, 2020) processes that underlie psychopathology.

Although these psychopathology dimensions are typically defined in terms of the covariation among psychiatric disorders only (Forbes et al., 2021; Greene \& Eaton, 2017; Krueger, 1999; cf Krueger et al., 2007), phenotypic and etiological associations between internalizing psychopathology and personality traits, such as the Big 5 (Costa \& McCrae, 1992), have been consistently demonstrated (Kotov et al., 2010; Walton et al., 2018; Watts et al., 2019a), suggesting the presence of a single dimension that underlies vulnerability to related 
psychopathology and personality traits (Krueger et al., 2002). Extant research on the phenotypic overlap between internalizing psychopathology and personality suggests that neuroticism and (reversed) conscientiousness have domain-general associations such that they are similarly associated with a broad range of internalizing disorders to a similar degree (Anderson \& Hope, 2008; Griffith et al., 2010; John et al., 1994; Kotov et al., 2010; Walton et al., 2018). In contrast, extraversion appears to have disorder-specific associations with depression and social anxiety (Kotov et al., 2010; Walton et al., 2018; Watts et al., 2019a). In fact, positive affect, which is closely related to Extraversion, distinguishes depression- and anxiety-related disorders, with depressive disorders, but not generalized anxiety, showing associations with lower levels of positive affect (see Anderson \& Hope, 2008 for review). Most studies have not found evidence of associations between internalizing disorders and openness to experience or agreeableness, although using the sample presented in this study, Watts and colleagues (2019a) found a weak negative association between agreeableness and a latent factor composed of depression, generalized anxiety, and social anxiety (Watts et al., 2019a).

Mirroring phenotypic findings, quantitative genetic studies using twins have found positive genetic correlations between neuroticism and several internalizing disorders, including social phobia (Bienvenu et al., 2007; Welander-Vatn et al., 2018), agoraphobia (Bienvenu et al., 2007), animal phobia (Bienvenu et al., 2007), generalized anxiety (Hettema et al., 2004), obsessive compulsive disorder symptoms (Hur, 2009), and depression (Fanous et al., 2002). The magnitude of these correlations varies by disorder, but they tend to be moderate to large (range $=$ .60 to .95$)$. Quantitative genetic studies also indicate that extraversion shares genetic variance with various internalizing disorders, although these correlations are negative and small to moderate in magnitude (range $=0$ to -.52 ; Bienvenu et al., 2007; Kendler \& Myers, 2014). 
Although many internalizing disorders are genetically associated with neuroticism and extraversion to a similar degree, there is some evidence that these associations vary by disorder (Bienvenu et al., 2007; Fanous et al., 2002; Jardine et al., 1984; Kendler \& Myers, 2014). For example, after accounting for the genetic variance that individual anxiety disorders shared with neuroticism and extraversion, social phobia and agoraphobia had no remaining unique genetic variance, whereas animal phobia had significant unique genetic variance (Bienvenu et al., 2007). In addition to evidence that personality traits and internalizing disorders are influenced by common genetic factors, studies have shown that they are influenced by common nonshared environmental factors, although the degree of overlap tends to be much smaller in magnitude (Bienvenu et al., 2007; Fanous et al., 2002; Hettema et al., 2006).

Despite the aforementioned utility of studying broad dimensions of psychopathology, most research examining the phenotypic and etiological associations between internalizing psychopathology and personality traits have examined these associations using individual internalizing disorders. Less is known about the associations between personality traits and broad, transdiagnostic dimensions of psychopathology (cf Walton et al., 2018; Watts et al., 2019a) and the degree to which individual disorders are uniquely associated with personality traits over and above what is shared between the personality trait and a broad internalizing dimension. Although some studies have found that individual internalizing disorders manifest different profiles of phenotypic (Kotov et al., 2010) and etiological (Bienvenu et al., 2007) associations, we are unable to conclude that these relationships are truly unique without first accounting for what personality shares with a broad internalizing dimension. To our knowledge, only one study has examined the unique phenotypic associations between personality traits and internalizing disorders after accounting for the formers' association with a broad internalizing 
dimension in this way (Watts et al., 2019a). In the sample used in the present study, Watts and colleagues (2019a) found that a broad internalizing dimension accounted for most of the phenotypic associations between internalizing psychopathology and personality. Nevertheless, they found evidence of small, unique phenotypic associations between social anxiety and extraversion, neuroticism and depression, GAD and social anxiety, openness and social anxiety, and agreeableness and compulsions, over and above these personality traits' associations with a broad internalizing dimension.

\section{The Current Study}

In this study, we extend this previous phenotypic work (Watts et al., 2019a) by examining the extent to which common etiological influences underlie the phenotypic overlap between internalizing psychopathology and personality traits. Specifically, we (1) examine the extent to which a broad internalizing dimension shares genetic and environmental influences with individual personality traits, and (2) estimate the unique etiological associations between individual internalizing disorders and personality traits after accounting for what they share with a broad internalizing dimension. To accomplish these goals, we first examined the extent to which all Big Five personality dimensions share genetic and environmental variance with internalizing psychopathology, operationalized as a broad internalizing dimension on which specific symptom dimensions load. Second, we examined whether individual internalizing disorders share etiological variance with all Big 5 personality dimensions after accounting for what they share with a broad internalizing dimension. These findings may have important implications for our understanding of the performance of broad dimensions of psychopathology, the etiological overlap between internalizing psychopathology and personality, and the mechanisms by which this overlap arises. 


\section{Method}

\section{Participants}

Participants were a subsample of the Georgia Twin Registry, a representative sample of twins (51\% female) born in Georgia between 1980 and $1991\left(M_{\text {age }}=8.5, S D=2.9\right.$, range 4 to 19), for whom information on psychopathology and personality were available $(N=448$ twin pairs). Participants were identified through birth records obtained for all twins born in the state of Georgia between 1980 and 1991. Families of twins were asked to join the Georgia Twin Registry and those who did were mailed a set of questionnaires, including those used in the current study. Mothers typically completed the questionnaires (53\%), and the remaining questionnaires were completed either by fathers alone $(1 \%)$ or both mothers and fathers together $(46 \%)$. Regarding ethnicity, $82 \%$ were of European ancestry, $11 \%$ of African ancestry, $1 \%$ Hispanic, and 6\% of mixed ethnicity. The sample comprised 206 monozygotic twin pairs (MZ; 46\%) and 242 dizygotic twin pairs (DZ; 54\%). Twin zygosity was determined from parental reports of the physical similarity of the twins using a 9-item scale previously validated against DNA polymorphisms (Bønnelykke et al., 1989). Parents provided written informed consent to a research protocol approved by the institutional review board at Emory University.

\section{Measures}

Internalizing Psychopathology. Internalizing psychopathology was measured using the Emory Combined Rating Scales (Waldman et al., 1998). The ECRS comprises symptoms of common DSM-IV childhood psychiatric diagnoses, such that each item reflects one symptom criteria from the DSM-IV. The ECRS measures internalizing disorders including Major Depression, Generalized Anxiety Disorder (GAD), Social Phobia, Obsessive-Compulsive Disorder (OCD; separated into Obsessions and Compulsions), Separation Anxiety Disorder, and 
Agoraphobia. Parents rated their children on each item using a 5-point Likert-type scale (0 indicated that the item did not describe the child well and 4 indicated that the item described the child very well). Symptom dimensions of each scale were calculated by averaging the child's symptom scores across the items within each of these respective scales. Each child's mean symptom scores thus ranged from 0 to 4 per symptom dimension, indicating the severity of his or her presentation. Previous studies demonstrated construct validity of the symptom scales (Ficks et al., 2013; Watts et al., 2019a) and, in the current study, Cronbach's alphas ranged from .54 (agoraphobia) to 90 (GAD).

Big Five Personality Questionnaire (BFPQ; Lanthier, 1993). The BFPQ was designed to obtain self- and other-reports of the Big Five personality dimensions in children and adolescents. It comprises 60 personality adjectives designed to reflect the personality domains of the five-factor model (Neuroticism, Extraversion, Openness, Agreeableness, and Conscientiousness). This measure was created by combining adjectives from well-established five-factor model inventories (Goldberg, 1990; McCrae \& Costa, 1997), including the Big Five Inventory (John et al., 1991) and the NEO Personality Inventory-Revised (Costa \& McCrae, 1992), and adjective-based measures (Saucier, 1997). Each of the 5 dimensions is represented by 12 items (Cronbach’s alphas ranged from .73 [Openness to Experience] to .90 [Conscientiousness]).

\section{Data Analysis}

All analyses were conducted using Mplus (Version 8; Muthén \& Muthén, 1998-2017) using full-information maximum likelihood (FIML), which produces less biased parameter estimates compared with listwise and pairwise deletion in the presence of missing data (Enders $\&$ Bandalos, 2001). The objective of our analyses was two-fold. First, we investigated the degree 
to which a broad internalizing dimension shared genetic and environmental influences with individual personality traits. Second, we tested the extent to which the etiological associations between specific internalizing disorders and personality traits operate through a broad internalizing dimension, versus in a disorder-specific manner. In other words, we examined whether a broad internalizing dimension accounted for the etiological associations between each personality trait and individual internalizing disorders, or whether each personality trait has unique associations with individual disorders after accounting for a broad internalizing dimension.

We began by modeling an internalizing psychopathology factor, a single dimension onto which all internalizing disorders loaded. Due to our sample size, the number of parameters estimated, and low variance of certain internalizing disorders, we were not able to estimate the measurement and quantitative genetic models simultaneously. Instead, we fit common factor models, in which all internalizing symptom dimensions loaded onto a single factor, for twin one and twin two separately. From these models, we saved factor scores representing twin one and twin two's internalizing scores to carry forward into the quantitative genetic models.

We next fit a series of quantitative genetic models. Quantitative genetic studies parse the variance in traits into four major components, two genetic and two environmental: additive genetic influences (A), nonadditive genetic influences (D), shared environmental influences (C), and nonshared environmental influences/measurement error (E). These components are estimated from differences in the correlations between monozygotic (MZ, or identical) twins, who share $100 \%$ of their segregating DNA, and dizygotic (DZ, or fraternal) twins, who share an average of $50 \%$ of their segregating DNA. Twin studies assume that twins of both zygosities have equivalent trait-relevant environments, an assumption that is generally supported in the 
literature (Felson, 2014; LoParo \& Waldman, 2014) Greater correlations between MZ twins compared with those for DZ twins thus imply genetic influences, whereas MZ twin correlations less than 1.0 imply nonshared environmental influences. Regarding environmental influences, shared environmental influences include all aspects of the trait-relevant environment that twins share which make them more similar on that trait, whereas nonshared environmental influences include all aspects of the environment that twins experience uniquely which make them different on that trait. We also estimated models with and without sibling interaction parameters (s) to account for rater contrast effects or cooperation/competition among twins (Neale \& Cardon, 1992). In univariate twin models, cross-twin correlations for a single phenotype are used to partition the observed variance into $\mathrm{A}, \mathrm{C}, \mathrm{D}$, and/or E components. In multivariate models, the twin model can be extended to explore the contributions of genetic and environmental factors to the observed covariance between two or more phenotypes (Neale \& Cardon, 1992).

Previous studies in adults, adolescents, and children have demonstrated that Big Five personality traits are influenced only by additive genetic and nonshared environmental influences (Briley \& Tucker-Drob, 2012; De Fruyt et al., 2006; Kandler \& Papendick, 2017; Lewis et al., 2014); thus, we tested multivariate models with only A and E parameters on personality dimensions. The role of the shared environment in the development of internalizing disorders is less clear (Bienvenu et al., 2007; Hettema et al., 2001; Hettema et al., 2006), so we first conducted univariate quantitative genetic analyses on all internalizing disorders and internalizing factor scores.

We next performed two sets of multivariate quantitative genetic analyses. First, we conducted a series of bivariate Cholesky decomposition analyses, to estimate the degree to which a broad internalizing dimension shares genetic and environmental influences with each 
personality trait (Figure 1a). Cholesky decompositions partition the total variance in two or more phenotypes and their covariance into latent genetic and environmental components (Neale \& Cardon, 1992). Second, we performed a series of trivariate Cholesky decomposition analyses to estimate the unique genetic and environmental associations between each personality trait and specific internalizing disorders after accounting for the broad internalizing dimension (Figure 1b). More specifically, we estimated the common genetic and environmental influences among all dimensions included (i.e., broad internalizing, a personality trait, and an individual internalizing disorder) while also estimating genetic and environmental influences unique to each dimension. We residualized all variables on age and sex covariates (i.e., age, age ${ }^{2}$, sex, sex*age, and sex $\left.{ }^{*} \operatorname{age}^{2}\right)$ in the quantitative genetic models.

We relied primarily on the magnitude and significance of the relevant parameters to evaluate the extent to which individual disorders manifested unique associations with personality over and above a broad internalizing dimension (path a23 in Figure 1b). In addition, we compared the fit of the fully saturated Cholesky decomposition models with nested submodels, in which specific paths were dropped one at a time. For example, to test the necessity of the path specifying a unique genetic relationship between individual internalizing disorders and a specific personality trait (path a23 in Figure 1b), we compared the fit of the fully saturated model to a model in which that path was dropped.

Fit indices indicate the overall performance of the model as a function of the discrepancy between the covariance matrix implied by the model and the covariance matrix in the observed data. The Tucker Lewis Index (TLI), root mean square error of approximation (RMSEA) and standardized root mean square residual (SRMR) were used to evaluate the fit of models individually using accepted conventions for the thresholds representing good fit. Higher TLI 
values indicate better fit, with values $\geq .95$ indicating good fit (Hu \& Bentler, 1999). Lower

RMSEA and SRMR values indicate better fit, with values $<.05$ and $<.08$, respectively, indicating good fit (DiStefano et al., 2018; Hu \& Bentler, 1999). $\chi 2$ statistics were not used to adjudicate among models but are reported because they give rise to the other fit indices. As is common in the behavior genetic literature (Loehlin, 2004; Markon \& Krueger, 2006), we relied primarily on BIC to adjudicate between quantitative genetic models, although we considered all model fit indices in assessing relative fit. Lower BIC values indicate better fit and BIC differences greater than 10 represent strong evidence in favor of the model with lower BIC (Raftery, 1995).

\section{Results}

\section{Does Personality Share Etiological Variance with Internalizing?}

A broad factor onto which all internalizing disorders loaded fit well for Twin One $\left(X^{2}=\right.$ $69, \mathrm{df}=27 ; \mathrm{RMSEA}=.04 ; \mathrm{TLI}=.87 ; \mathrm{SRMR}=.05)$ and Twin Two $\left(X^{2}=68, \mathrm{df}=27 ; \mathrm{RMSEA}=\right.$ $.04 ; \mathrm{TLI}=.87 ; \mathrm{SRMR}=.05)$ as RMSEA and SRMR values, but not TLI values, were within recommended ranges indicating good fit. The broad internalizing dimension and the individual internalizing disorders were best characterized by AE models, each with appreciable genetic influences and moderate nonshared environmental influences (Supplemental Table 1). Agoraphobia also had a small, but significant, and negative sibling interaction parameter.

Broad internalizing shared a significant percent of its genetic variance with Neuroticism $\left(\mathrm{a}^{2}\right.$ shared $\left.=.22,95 \% \mathrm{CI}=.08, .44\right)$, Extraversion $\left(\mathrm{a}^{2}\right.$ shared $\left.=.04,95 \% \mathrm{CI}=.002, .12\right)$, Agreeableness $\left(\mathrm{a}^{2}\right.$ shared $\left.=.04,95 \% \mathrm{CI}=.01, .10\right)$, and Conscientiousness $\left(\mathrm{a}^{2}\right.$ shared $\left.=.06,95 \% \mathrm{CI}=.005, .18\right)$. The broad internalizing dimension did not have a significant proportion of common nonshared 
environmental influences with any of the personality traits $\left(\mathrm{e}^{2}\right.$ shared ranged from $.00-.01$, all $p$ s $>$ $.05)$.

\section{Do Specific Internalizing Disorders Share Unique Etiological Variance with Personality?}

For the most part, etiological associations between personality and internalizing were captured by the broad internalizing factor, as evidenced by their nonsignificant path coefficients and lack of a decrement in model fit when those paths were dropped (see Supplemental Tables 28). There were, however, some exceptions.

In terms of unique additive genetic associations, social anxiety shared significant additive genetic variance with Neuroticism and Extraversion $\left(\mathrm{a}^{2}\right.$ shared $=.07[95 \% \mathrm{CI}=.0005, .25]$ and .04 $[95 \% \mathrm{CI}=.01, .11]$, respectively) over and above the genetic variance it shared with the broad internalizing dimension (Table 1, Figure 1, and Supplemental Table 6). Major Depression shared significant additive genetic influences with Agreeableness $\left(\mathrm{a}^{2}\right.$ shared $=.02[95 \% \mathrm{CI}=.001, .07]$; Supplemental Table 2) and Compulsions shared significant additive genetic influences with Conscientiousness $\left(\mathrm{a}^{2}\right.$ shared $=.03[95 \% \mathrm{CI}=.0001, .13]$; Supplemental Table 5).

In terms of unique nonshared environmental associations, Major Depression shared significant nonshared environmental variance with Neuroticism and Conscientiousness $\left(\mathrm{e}^{2}\right.$ shared $=$ $.01[95 \% \mathrm{CI}=.0001, .02]$ and $\mathrm{e}^{2}$ shared $=.01[95 \% \mathrm{CI}=.002, .04]$, respectively), although dropping these paths did not result in a substantial decrement in model fit (Supplemental Tables 2).

\section{Discussion}

\section{Interpretation \& Implications of Findings}

In this study, we investigated the nature of phenotypic and etiologic relationships between internalizing psychopathology and Big 5 personality traits. We employed both broad and specific operationalizations of internalizing, first examining associations between a broad 
internalizing factor and each personality trait and then examining whether there were unique associations between individual internalizing disorders and each personality trait after accounting for what the personality trait shared with broad internalizing.

As an extension of the previous literature, we demonstrated that established phenotypic associations between Big Five personality traits and internalizing psychopathology (e.g., Kotov et al., 2010; Watts et al., 2019a) appear in large part because the two sets of constructs share additive genetic, but not environmental, influences. More specifically, consistent with previous literature (Bienvenu et al., 2007; Fanous et al., 2002; Hettema et al., 2006; Hettema et al., 2004; Hur, 2009; Welander-Vatn et al., 2018) and mirroring well-established phenotypic findings (Kotov et al., 2010), we found that the broad internalizing dimension shared significant additive genetic influences with Neuroticism, Extraversion, and Conscientiousness. Although existing studies have found mixed evidence of weak environmental correlations between personality and internalizing (Bienvenu et al., 2007; Fanous et al., 2002; Hettema et al., 2006), we found no evidence that the two constructs had common nonshared environmental influences. The finding that broad internalizing shares additive genetic influences with Neuroticism, Extraversion, and Conscientiousness is particularly noteworthy, as other research has shown that depression, specifically, reflects the statistical interaction among these three Big Five traits, suggesting that internalizing may reflect a configuration of these traits (e.g., Vasey et al., 2013).

Somewhat surprisingly, we found that Agreeableness shared significant additive genetic variance with broad internalizing. Most studies indicate that externalizing, but not internalizing, is associated with (reversed) agreeableness (i.e., Antagonism; De Bolle et al., 2012; John et al., 1994; Kotov et al., 2010). We offer two non-mutually exclusive explanations for this finding. First, our measure of agreeableness includes items reflecting irritability and social warmth, 
which, coupled with the observational nature of parent ratings, may lead to disturbances in mood (i.e., presence of internalizing psychopathology) being reflected in lower agreeableness. It is also noteworthy that the negative emotionality dimension within Oppositional Defiant Disorder, which includes indicators of irritability, shares genetic variance with and longitudinally predicts later depression (Burke et al., 2010; Waldman et al., 2018). Second, internalizing and externalizing psychopathology tend to be moderately correlated in youth as well as in adults (Eaton et al., 2011; Krueger, 1999; Watts et al., 2019b) and it is possible that agreeableness serves as a transdiagnostic indicator of psychopathological distress.

We also investigated the extent to which individual internalizing disorders share etiological variance with personality traits after accounting for what personality traits share with broad internalizing. A broad internalizing dimension adequately captured the variance shared between internalizing disorders and personality such that, with few exceptions, we did not find evidence of unique associations between individual internalizing disorders and personality dimensions. This finding reinforces the utility of higher-order psychopathology dimensions outlined in HiTOP (e.g., Kotov et al., 2017). In fact, our findings show that studying broad dimensions in most cases may be preferable to studying disorders in isolation because the former allows for the most comprehensive and simultaneously parsimonious conceptualization of internalizing. For example, if we were to focus exclusively on depression, we might prematurely conclude that it is uniquely genetically associated with Neuroticism, despite the fact that Neuroticism is associated with internalizing disorders more generally. Thus, broad, transdiagnostic dimensions may serve as more robust targets in genetic and neurobiological investigations, as well as in broader studies of the development, etiology, and course of psychopathology. 
Still, there were a few notable examples of unique etiological associations between personality and individual disorders. First, social anxiety shared unique genetic variance with Neuroticism and Extraversion. The relationship between social anxiety and Extraversion is consistent with previous findings that suggest an especially strong phenotypic relationship between the two (Kotov et al., 2010). This finding is also theoretically coherent given the overlap in presentation and suggests the possibility that social anxiety is an extreme manifestation of low extraversion, such that they may each lie on different ends of the same dimension. Second, depression shared unique genetic variance with Agreeableness, which may be driven by the fact that agreeableness contains items related to positive social warmth and irritability (Caspi \& Shiner, 2008; Watts et al., 2019a). Indeed, the magnitude of additive genetic variance shared between Agreeableness and broad internalizing was similar to the unique variance it shares with depression, suggesting that depression may have driven the association between broad internalizing and Agreeableness. Fourth, our finding that Conscientiousness and compulsions share unique genetic variance suggests, again, that compulsions may represent an extreme manifestation of conscientiousness (Carter et al., 2016; Mike et al., 2018).

\section{Limitations and Future Directions}

These novel findings should be interpreted with a few important limitations in mind. First, we relied on parent-report to characterize internalizing psychopathology and personality dimensions. Use of mono-informant reports increases the risk of response biases and rater effects that can give rise to spuriously high correlations among variables (De Los Reyes et al., 2015; Martel et al., 2017). Future studies should include multi-informant reports, which could include parent, teacher, and self-reports, to minimize or account for potential rater bias (Achenbach et al., 1987; Martel et al., 2017). Second, classical twin designs, as used in the current study, are 
limited by their inattention to assortative mating and gene-environment covariance, the presence of which biases the estimates of additive genetic influences downwards. Many of these limitations are overcome by the use of extended twin family designs, which make use of a wider range of related individuals and are able to estimate all four sources of etiological influence simultaneously (Keller et al., 2010). Third, our measure of the Big Five assessed personality at

the domain-level only, precluding our ability to detect associations between internalizing and facets of each Big 5 dimensions (e.g., Allen et al., 2018). Fourth, and finally, although our findings have important implications for our understanding of the etiological associations between internalizing psychopathology and personality, we are unable to comment on specific genetic and environmental mechanisms that give rise to these relationships. Future studies should endeavor to extend these results by employing genetic methods that can be used to understand the potential specific underlying causal relationships between variables, such as multimodal inference and model averaging (Maes et al., 2021) and Mendelian Randomization and its extensions (Emdin et al., 2017; Minică et al., 2018).

\section{References}

Achenbach, T. M. (1966). The classification of children's psychiatric symptoms: A factoranalytic study. Psychological Monographs: General and Applied, 80(7), 1-37. https://doi.org/doi.org/10.1037 
Achenbach, T. M., McConaughy, S. H., \& Howell, C. T. (1987). Child/adolescent behavioral and emotional problems: Implications of cross-informant correlations for situational specificity. Psychological Bulletin, 101(2), 213-232. https://doi.org/10.1037/0033$\underline{2909.101 .2 .213}$

Allen, T. A., Carey, B. E., McBride, C., Bagby, R. M., DeYoung, C. G., \& Quilty, L. C. (2018). Big five aspects of personality interact to predict depression. Journal of Personality, 86(4), 714-725. https://doi.org/https://doi.org/10.1111/jopy.12352

Anderson, E. R., \& Hope, D. A. (2008). A review of the tripartite model for understanding the link between anxiety and depression in youth. Clinical Psychology Review, 28(2), 275287. https://doi.org/https://doi.org/10.1016/j.cpr.2007.05.004

Bienvenu, O. J., Hettema, J. M., Neale, M. C., Prescott, C. A., \& Kendler, K. S. (2007). Low extraversion and high neuroticism as indices of genetic and environmental risk for social phobia, agoraphobia, and animal phobia. American Journal of Psychiatry, 164(11), 17141721. https://doi.org/10.1176/appi.ajp.2007.06101667

Bønnelykke, B., Hauge, M., Holm, N., Kristoffersen, K., \& Gurtler, H. (1989). Evaluation of zygosity diagnosis in twin pairs below age seven by means of a mailed questionnaire Acta geneticae medicae et gemellologiae: twin research, 38(3-4), 305-313.

Briley, D. A., \& Tucker-Drob, E. M. (2012). Broad bandwidth or high fidelity? Evidence from the structure of genetic and environmental effects on the facets of the five factor model. Behavior Genetics, 42(5), 743-763. https://doi.org/10.1007/s10519-012-9548-8

Burke, J. D., Hipwell, A. E., \& Loeber, R. (2010). Dimensions of oppositional defiant disorder as predictors of depression and conduct disorder in preadolescent girls. Journal of the American Academy of Child and Adolescent Psychiatry, 49(5), 484-492. 
Carter, N. T., Guan, L., Maples, J. L., Williamson, R. L., \& Miller, J. D. (2016). The downsides of extreme conscientiousness for psychological well-being: The role of obsessive compulsive tendencies [https://doi.org/10.1111/jopy.12177]. Journal of Personality, 84(4), 510-522. https://doi.org/https://doi.org/10.1111/jopy.12177

Caspi, A., \& Shiner, R. (2008). Temperament and personality. In M. Rutter, D. V. M. Bishop, D. S. Pine, S. Scott, J. Stenvenson, E. Taylor, \& A. Thapar (Eds.), Rutter's child and adolescent psychiatry Blackwell Publishing Limited.

Costa, P. T., \& McCrae, R. R. (1992). Revised neo personality inventory (neo-pi-r) and neo fivefactor (neo-ffi) inventory professional manual. Psychological Assessment Resources, Incorporated.

De Bolle, M., Beyers, W., De Clercq, B., \& De Fruyt, F. (2012). General personality and psychopathology in referred and nonreferred children and adolescents: An investigation of continuity, pathoplasty, and complication models. Journal of Abnormal Psychology, 121(4), 958-970. https://doi.org/10.1037/a0027742

De Fruyt, F., Bartels, M., Van Leeuwen, K. G., De Clercq, B., Decuyper, M., \& Mervielde, I. (2006). Five types of personality continuity in childhood and adolescence. Journal of Personality and Social Psychology, 91(3), 538-552. https://doi.org/10.1037/0022-

\section{$\underline{3514.91 .3 .538}$}

De Los Reyes, A., Augenstein, T. M., Wang, M., Thomas, S. A., Drabick, D. A. G., Burgers, D. E., \& Rabinowitz, J. (2015). The validity of the multi-informant approach to assessing child and adolescent mental health. Psychological Bulletin, 141(4), 858-900. https://www.ncbi.nlm.nih.gov/pubmed/25915035 
Dick, D. M., Aliev, F., Wang, J. C., Grucza, R. A., Schuckit, M., Kuperman, S., . . Goate, A. (2008). Using dimensional models of externalizing psychopathology to aid in gene identification. Archives of General Psychiatry, 65(3), 310-318. https://doi.org/10.1001/archpsyc.65.3.310

DiStefano, C., Liu, J., Jiang, N., \& Shi, D. (2018). Examination of the weighted root mean square residual: Evidence for trustworthiness? Structural Equation Modeling: A Multidisciplinary Journal, 25(3), 453-466. https://doi.org/10.1080/10705511.2017.1390394

Eaton, N. R., Krueger, R. F., Keyes, K. M., Skodol, A. E., Markon, K. E., Grant, B. F., \& Hasin, D. S. (2011). Borderline personality disorder co-morbidity: Relationship to the internalizing-externalizing structure of common mental disorders. Psychological Medicine, 41(5), 1041-1050. https://doi.org/10.1017/S0033291710001662

Emdin, C. A., Khera, A. V., \& Kathiresan, S. (2017). Mendelian randomization. JAMA, 318(19), 1925-1926. https://doi.org/10.1001/jama.2017.17219

Enders, C., \& Bandalos, D. (2001). The relative performance of full information maximum likelihood estimation for missing data in structural equation models. Structural Equation Modeling: A Multidisciplinary Journal, 8(3), 430-457. https://doi.org/10.1207/S15328007SEM0803_5

Fanous, A., Gardner, C. O., Prescott, C. A., Cancro, R., \& Kendler, K. S. (2002). Neuroticism, major depression and gender: A population-based twin study. Psychological Medicine, 32(4), 719-728. https://doi.org/10.1017/S003329170200541X 
Felson, J. (2014). What can we learn from twin studies? A comprehensive evaluation of the equal environments assumption. Social Science Research, 43, 184-199. https://doi.org/10.1016/j.ssresearch.2013.10.004

Ficks, C. A., Lahey, B. B., \& Waldman, I. D. (2013). Does low birth weight share common genetic or environmental risk with childhood disruptive disorders? J Abnorm Psychol, 122(3), 842-853. https://doi.org/10.1037/a0033079

Forbes, M. K., Greene, A. L., Levin-Aspenson, H. F., Watts, A. L., Hallquist, M., Lahey, B. B., . . Krueger, R. F. (2021). Three recommendations based on a comparison of the reliability and validity of the predominant models used in research on the empirical structure of psychopathology. Journal of Abnormal Psychology, 130(3), 297-317.

\section{https://doi.org/10.1037/abn0000533}

Goldberg, L. R. (1990). An alternative "description of personality": The big-five factor structure. Journal of Personality and Social Psychology, 59(6), 1216-1229. https://doi.org/10.1037/0022-3514.59.6.1216

Grabow, A. P., Khurana, A., Natsuaki, M. N., Neiderhiser, J. M., Harold, G. T., Shaw, D. S., . . Leve, L. D. (2017). Using an adoption-biological family design to examine associations between maternal trauma, maternal depressive symptoms, and child internalizing and externalizing behaviors. Development and Psychopathology, 29(5), 1707-1720. https://doi.org/10.1017/S0954579417001341

Greene, A. L., \& Eaton, N. R. (2017). The temporal stability of the bifactor model of comorbidity: An examination of moderated continuity pathways. Comprehensive Psychiatry, 72, 74-82. https://doi.org/https://doi.org/10.1016/j.comppsych.2016.09.010 
Griffith, J. W., Zinbarg, R. E., Craske, M. G., Mineka, S., Rose, R. D., Waters, A. M., \& Sutton, J. M. (2010). Neuroticism as a common dimension in the internalizing disorders. Psychological Medicine, 40(7), 1125-1136. https://doi.org/10.1017/S0033291709991449

Hettema, J. M., Neale, M. C., \& Kendler, K. S. (2001). A review and meta-analysis of the genetic epidemiology of anxiety disorders. American Journal of Psychiatry, 158(10), 1568-1578. https://doi.org/10.1176/appi.ajp.158.10.1568

Hettema, J. M., Neale, M. C., Myers, J. M., Prescott, C. A., \& Kendler, K. S. (2006). A population-based twin study of the relationship between neuroticism and internalizing disorders. American Journal of Psychiatry, 163(5), 857-864. https://doi.org/10.1176/ajp.2006.163.5.857

Hettema, J. M., Prescott, C. A., \& Kendler, K. S. (2004). Genetic and environmental sources of covariation between generalized anxiety disorder and neuroticism. American Journal of Psychiatry, 161(9), 1581-1587. https://doi.org/10.1176/appi.ajp.161.9.1581

Hu, L. t., \& Bentler, P. M. (1999). Cutoff criteria for fit indexes in covariance structure analysis: Conventional criteria versus new alternatives. Structural Equation Modeling: A Multidisciplinary Journal, 6(1), 1-55. https://doi.org/10.1080/10705519909540118

Hur, Y.-M. (2009). Genetic and environmental covariations among obsessive-compulsive symptoms, neuroticism, and extraversion in south korean adolescent and young adult twins. Twin Research and Human Genetics, 12(2), 142-148.

\section{https://doi.org/10.1375/twin.12.2.142}

Jardine, R., Martin, N. G., Henderson, A. S., \& Rao, D. C. (1984). Genetic covariation between neuroticism and the symptoms of anxiety and depression 
[https://doi.org/10.1002/gepi.1370010202]. Genetic Epidemiology, 1(2), 89-107. https://doi.org/https://doi.org/10.1002/gepi.1370010202

John, O. P., Caspi, A., Robins, R. W., Moffitt, T. E., \& Stouthamer-Loeber, M. (1994). The "little five": Exploring the nomological network of the five-factor model ofpersonality in adolescent boys. Child Development 65(1), 160-178. https://doi.org/10.2307/1131373

John, O. P., Donahue, E. M., \& Kentle, R. L. (1991). The big five inventory-versions $4 a$ and 54. University of California, Berkeley, Institute of Personality and Social Research.

Kandler, C., \& Papendick, M. (2017). 29 - behavior genetics and personality development: A methodological and meta-analytic review. In J. Specht (Ed.), Personality development across the lifespan (pp. 473-495). Academic Press. https://doi.org/https://doi.org/10.1016/B978-0-12-804674-6.00029-6

Keller, M. C., Medland, S. E., \& Duncan, L. E. (2010). Are extended twin family designs worth the trouble? A comparison of the bias, precision, and accuracy of parameters estimated in four twin family models. Behavior Genetics, 40(3), 377-393.

https://doi.org/10.1007/s10519-009-9320-X

Kendler, K. S., \& Myers, J. (2014). The boundaries of the internalizing and externalizing genetic spectra in men and women. Psychological Medicine, 44(3), 647-655. https://doi.org/10.1017/S0033291713000585

Kotov, R., Gamez, W., Schmidt, F., \& Watson, D. (2010). Linking "big" personality traits to anxiety, depressive, and substance use disorders: A meta-analysis. Psychological Bulletin, 136(5), 768-821. https://doi.org/10.1037/a0020327

Krueger, Hicks, Patrick, Carlson, Iacono, \& McGue. (2002). Etiological connections among substance dependence, antisocial behavior, and personality: Modeling the externalizing 
spectrum. Journal of Abnormal Psychology, 111(3), 411-424.

https://doi.org/10.1037/0021-843X.111.3.411

Krueger, R. F. (1999). The structure of common mental disorders. Archives of General Psychiatry, 56(10), 921-926. https://doi.org/10.1001/archpsyc.56.10.921

Krueger, R. F., \& Markon, K. E. (2006). Reinterpreting comorbidity: A model-based approach to understanding and classifying psychopathology. Annual Review of Clinical Psychology, 2(1), 111-133. https://doi.org/10.1146/annurev.clinpsy.2.022305.095213

Krueger, R. F., Markon, K. E., Patrick, C. J., Benning, S. D., \& Kramer, M. D. (2007). Linking antisocial behavior, substance use, and personality: An integrative quantitative model of the adult externalizing spectrum. Journal of Abnormal Psychology, 116(4), 645-666.

Kuo, S. I. C., Salvatore, J. E., Barr, P. B., Aliev, F., Anokhin, A., Bucholz, K. K., . . Externalizing, C. (2021). Mapping pathways by which genetic risk influences adolescent externalizing behavior: The interplay between externalizing polygenic risk scores, parental knowledge, and peer substance use. Behavior Genetics. https://doi.org/10.1007/s10519-021-10067-7

Lanthier, R. P. (1993). The big five personality dimensions in middle childhood and adolescence University of Denver]. Dissertation Abstracts International

Lewis, G. J., Haworth, C. M. A., \& Plomin, R. (2014). Identical genetic influences underpin behavior problems in adolescence and basic traits of personality [https://doi.org/10.1111/jcpp.12156]. Journal of Child Psychology and Psychiatry, 55(8), 865-875. https://doi.org/https://doi.org/10.1111/jcpp.12156

Linnér, R. K., Mallard, T. T., Barr, P. B., Sanchez-Roige, S., Madole, J. W., Driver, M. N., ... Dick, D. M. (2020). Multivariate genomic analysis of 1.5 million people identifies genes 
related to addiction, antisocial behavior, and health. bioRxiv, 2020.2010.2016.342501. https://doi.org/10.1101/2020.10.16.342501

Loehlin, J. C. (2004). Latent variable models: An introduction to factor, path, and structural equation analysis. Psychology Press.

LoParo, D., \& Waldman, I. (2014). Twins' rearing environment similarity and childhood externalizing disorders: A test of the equal environments assumption. Behavior Genetics, 44(6), 606-613. https://doi.org/10.1007/s10519-014-9685-3

Maes, H. H., Neale, M. C., Kirkpatrick, R. M., \& Kendler, K. S. (2021). Using multimodel inference/model averaging to model causes of covariation between variables in twins. Behavior Genetics, 51(1), 82-96. https://doi.org/10.1007/s10519-020-10026-8

Marceau, K., Laurent, H. K., Neiderhiser, J. M., Reiss, D., Shaw, D. S., Natsuaki, M. N., .. . Leve, L. D. (2015). Combined influences of genes, prenatal environment, cortisol, and parenting on the development of children's internalizing versus externalizing problems. Behavior Genetics, 45(3), 268-282. https://doi.org/10.1007/s10519-014-9689-z

Marceau, K., \& Neiderhiser, J. (2020). Generalist genes and specialist environments for adolescent internalizing and externalizing problems: A test of severity and directionality. Development and Psychopathology, 1-8. https://doi.org/10.1017/S0954579420001108

Markon, K. E., \& Krueger, R. F. (2006). Information-theoretic latent distribution modeling: Distinguishing discrete and continuous latent variable models. Psychological Methods, 11(3), 228-243. https://doi.org/10.1037/1082-989X.11.3.228.supp

Martel, M. M., Markon, K., \& Smith, G. T. (2017). Research review: Multi-informant integration in child and adolescent psychopathology diagnosis. Journal of Child Psychology and Psychiatry and Allied Disciplines, 58(2), 116-128. https://doi.org/10.1111/jcpp.12611 
McCrae, R. R., \& Costa, P. T. (1997). Personality trait structure as a human universal. American Psychologist, 52(5), 509-516. https://doi.org/10.1037/0003-066X.52.5.509

Mike, A., King, H., Oltmanns, T. F., \& Jackson, J. J. (2018). Obsessive, compulsive, and conscientious? The relationship between ocpd and personality traits [https://doi.org/10.1111/jopy.12368]. Journal of Personality, 86(6), 952-972. https://doi.org/https://doi.org/10.1111/jopy.12368

Minică, C. C., Dolan, C. V., Boomsma, D. I., de Geus, E., \& Neale, M. C. (2018). Extending causality tests with genetic instruments: An integration of mendelian randomization with the classical twin design. Behavior Genetics, 48(4), 337-349. https://doi.org/10.1007/s10519-018-9904-4

Muthén, L. K., \& Muthén, B. O. (1998-2017). Mplus user's guide. Eighth edition. Muthén \& Muthén.

Neale, M. C., \& Cardon, L. R. (1992). Methodology for genetic studies of twins and families. Kluwer Academic.

Raftery, A. E. (1995). Bayesian model selection in social research. Sociological Methodology, 25, 111-163. https://doi.org/10.2307/271063

Saucier, G. (1997). Effects of variable selection on the factor structure of person descriptors. Journal of Personality and Social Psychology, 73, 1296-1312.

Vasey, M. W., Harbaugh, C. N., Lonigan, C. J., Phillips, B. M., Hankin, B. L., Willem, L., \& Bijttebier, P. (2013). Dimensions of temperament and depressive symptoms: Replicating a three-way interaction. Journal of Research in Personality, 47(6), 908-921. https://doi.org/https://doi.org/10.1016/j.jrp.2013.09.001 
Waldman, I. D., Rowe, D. C., Abramowitz, A., Kozel, S. T., Mohr, J. H., Sherman, S. L., . . Stever, C. (1998). Association and linkage of the dopamine transporter gene and attention-deficit hyperactivity disorder in children: Heterogeneity owing to diagnostic subtype and severity. American Journal of Human Genetics, 63(6), 1767-1776. https://doi.org/10.1086/302132

Waldman, I. D., Rowe, R., Boylan, K., \& Burke, J. D. (2018). External validation of a bifactor model of oppositional defiant disorder. Molecular Psychiatry. https://doi.org/10.1038/s41380-018-0294-Z

Walton, K. E., Pantoja, G., \& McDermut, W. (2018). Associations between lower order facets of personality and dimensions of mental disorder. Journal of Psychopathology and Behavioral Assessment, 40(3), 465-475. https://doi.org/10.1007/s10862-017-9633-7

Watts, A. L., Poore, H. E., Lilienfeld, S. O., \& Waldman, I. D. (2019a). Clarifying the associations between big five personality domains and higher-order psychopathology dimensions in youth. Journal of Research in Personality, 82. $\underline{\text { https://doi.org/10.1016/j.jrp.2019.07.002 }}$

Watts, A. L., Poore, H. E., \& Waldman, I. D. (2019b). Riskier tests of the validity of the bifactor model of psychopathology. Clinical Psychological Science, 7(6), 1285-1303. https://doi.org/10.1177/2167702619855035

Welander-Vatn, A., Torvik, F. A., Czajkowski, N., Kendler, K. S., Reichborn-Kjennerud, T., Knudsen, G. P., \& Ystrom, E. (2018). Relationships among avoidant personality disorder, social anxiety disorder, and normative personality traits: A twin study. Journal of Personality Disorders, 33(3), 289-309. https://doi.org/10.1521/pedi_2018_32_341 
Table 1

Common Etiological Variance between Little Five and Internalizing Dimensions

\begin{tabular}{|c|c|c|c|c|c|c|c|c|c|c|}
\hline \multirow[b]{2}{*}{ Dimension } & \multicolumn{2}{|c|}{ Neuroticism } & \multicolumn{2}{|c|}{ Extraversion } & \multicolumn{2}{|c|}{ Openness } & \multicolumn{2}{|c|}{ Agreeableness } & \multicolumn{2}{|c|}{ Conscientiousness } \\
\hline & $\mathbf{a}^{2}$ & $\mathrm{e}^{2}$ & $\mathbf{a}^{2}$ & $\mathrm{e}^{2}$ & $\overline{\mathbf{a}^{2}}$ & $\mathrm{e}^{2}$ & $\mathbf{a}^{2}$ & $\mathrm{e}^{2}$ & $\mathbf{a}^{2}$ & $\mathrm{e}^{2}$ \\
\hline Broad Internalizing & $\begin{array}{c}.22 \\
(.08, .44)\end{array}$ & $\begin{array}{c}.00 \\
(.00, .00)\end{array}$ & $\begin{array}{c}.04 \\
(.002, .12)\end{array}$ & $\begin{array}{c}.00 \\
(.00, .02)\end{array}$ & $\begin{array}{c}.01 \\
(.00, .04)\end{array}$ & $\begin{array}{c}.00 \\
(.00, .02)\end{array}$ & $\begin{array}{c}. .04 \\
(.01, .10)\end{array}$ & $\begin{array}{c}.00 \\
(.00, .00)\end{array}$ & $\begin{array}{c}.06 \\
(.005, .18)\end{array}$ & $\begin{array}{c}.01 \\
(.00, .03)\end{array}$ \\
\hline Major Depression & $\begin{array}{c}.00 \\
(.00, .04)\end{array}$ & $\begin{array}{c}.01 \\
(.0001, .02)\end{array}$ & $\begin{array}{c}.00 \\
(.00, .02)\end{array}$ & $\begin{array}{c}.01 \\
(.00, .04)\end{array}$ & $\begin{array}{c}.00 \\
(.00, .02)\end{array}$ & $\begin{array}{c}.00 \\
(.00, .01)\end{array}$ & $\begin{array}{c}.02 \\
(.001, .07)\end{array}$ & $\begin{array}{c}.00 \\
(.00, .02)\end{array}$ & $\begin{array}{c}.03 \\
(.00, .11)\end{array}$ & $\begin{array}{c}.01 \\
(.002, .03)\end{array}$ \\
\hline GAD & $\begin{array}{c}.00 \\
(.00, .04)\end{array}$ & $\begin{array}{c}.00 \\
(.00, .00)\end{array}$ & $\begin{array}{c}.00 \\
(.00, .01)\end{array}$ & $\begin{array}{c}.00 \\
(.00, .01)\end{array}$ & $\begin{array}{c}.00 \\
(.00, .00)\end{array}$ & $\begin{array}{c}.00 \\
(.00, .01)\end{array}$ & $\begin{array}{c}.00 \\
(.00, .01)\end{array}$ & $\begin{array}{c}.00 \\
(.00, .01)\end{array}$ & $\begin{array}{c}.00 \\
(.00, .01)\end{array}$ & $\begin{array}{c}.00 \\
(.00, .01)\end{array}$ \\
\hline Obsessions & $\begin{array}{c}.02 \\
(.00, .15)\end{array}$ & $\begin{array}{c}.00 \\
(.00, .02)\end{array}$ & $\begin{array}{c}.01 \\
(.00, .06)\end{array}$ & $\begin{array}{c}.00 \\
(.00, .02)\end{array}$ & $\begin{array}{c}.00 \\
(.00, .04)\end{array}$ & $\begin{array}{c}.00 \\
(.00, .03)\end{array}$ & $\begin{array}{c}.00 \\
(.00, .03)\end{array}$ & $\begin{array}{c}.00 \\
(.00, .02)\end{array}$ & $\begin{array}{c}.00 \\
(.00, .04)\end{array}$ & $\begin{array}{c}.00 \\
(.00, .01)\end{array}$ \\
\hline Compulsions & $\begin{array}{c}.03 \\
(.00, .17)\end{array}$ & $\begin{array}{c}.00 \\
(.00, .04)\end{array}$ & $\begin{array}{c}.00 \\
(.00, .02)\end{array}$ & $\begin{array}{c}.00 \\
(.00, .02)\end{array}$ & $\begin{array}{c}.00 \\
.00, .03)\end{array}$ & $\begin{array}{c}.01 \\
(.00, .05)\end{array}$ & $\begin{array}{c}.00 \\
(.00, .04)\end{array}$ & $\begin{array}{c}.00 \\
(.00, .03)\end{array}$ & $\begin{array}{c}.03 \\
.0001, .13)\end{array}$ & $\begin{array}{c}.01 \\
(.00, .06)\end{array}$ \\
\hline Social Anxiety & $\begin{array}{c}.07 \\
(.0005, .25)\end{array}$ & $\begin{array}{c}.00 \\
.00, .01)\end{array}$ & $\begin{array}{c}.04 \\
(.01, .14)\end{array}$ & $\begin{array}{c}.00 \\
(.00, .02)\end{array}$ & $\begin{array}{c}.01 \\
.00, .06)\end{array}$ & $\begin{array}{c}.00 \\
(.00, .03)\end{array}$ & $\begin{array}{c}.01 \\
(.00, .04)\end{array}$ & $\begin{array}{c}.01 \\
.00, .04)\end{array}$ & $\begin{array}{c}.01 \\
(.00, .08)\end{array}$ & $\begin{array}{c}.01 \\
(.00, .04)\end{array}$ \\
\hline Separation Anxiety & $\begin{array}{c}.00 \\
(.00, .04)\end{array}$ & $\begin{array}{c}.00 \\
(.00, .00)\end{array}$ & $\begin{array}{c}.00 \\
(.00, .01)\end{array}$ & $\begin{array}{c}.00 \\
(.00, .01)\end{array}$ & $\begin{array}{c}.00 \\
(.00, .01)\end{array}$ & $\begin{array}{c}.00 \\
(.00, .00)\end{array}$ & $\begin{array}{c}.00 \\
(.00, .02)\end{array}$ & $\begin{array}{c}.00 \\
(.00, .00)\end{array}$ & $\begin{array}{c}.01 \\
(.00, .04)\end{array}$ & $\begin{array}{c}.00 \\
(.00, .01)\end{array}$ \\
\hline Agoraphobia & $\begin{array}{c}.01 \\
(.00, .08) \\
\end{array}$ & $\begin{array}{c}.00 \\
(.00, .01) \\
\end{array}$ & $\begin{array}{c}.00 \\
(.00, .01) \\
\end{array}$ & $\begin{array}{c}.00 \\
(.00, .01) \\
\end{array}$ & $\begin{array}{c}.00 \\
(.00, .02)\end{array}$ & $\begin{array}{c}.00 \\
(.00, .01)\end{array}$ & $\begin{array}{c}.00 \\
(.00, .01) \\
\end{array}$ & $\begin{array}{c}.00 \\
(.00, .01) \\
\end{array}$ & $\begin{array}{c}.00 \\
(.00, .02) \\
\end{array}$ & $\begin{array}{c}.00 \\
(.00, .01) \\
\end{array}$ \\
\hline
\end{tabular}

Note. GAD = Generalized Anxiety Disorders; SAD = Separation Anxiety Disorder. Parameters significant at $p<.05$ are bolded.

Confidence intervals are bounded between 0 and 1 for variance components. 


\section{Figure 1}

Example Cholesky Models

a)

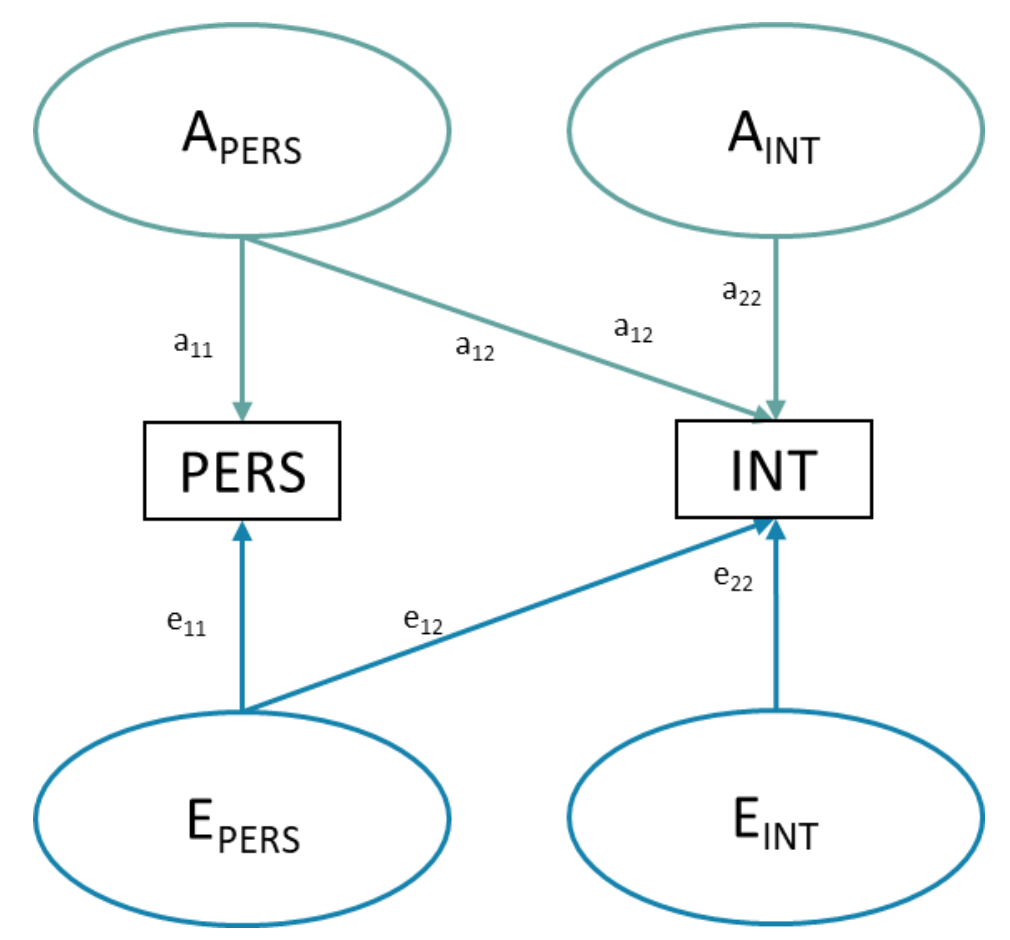

b)

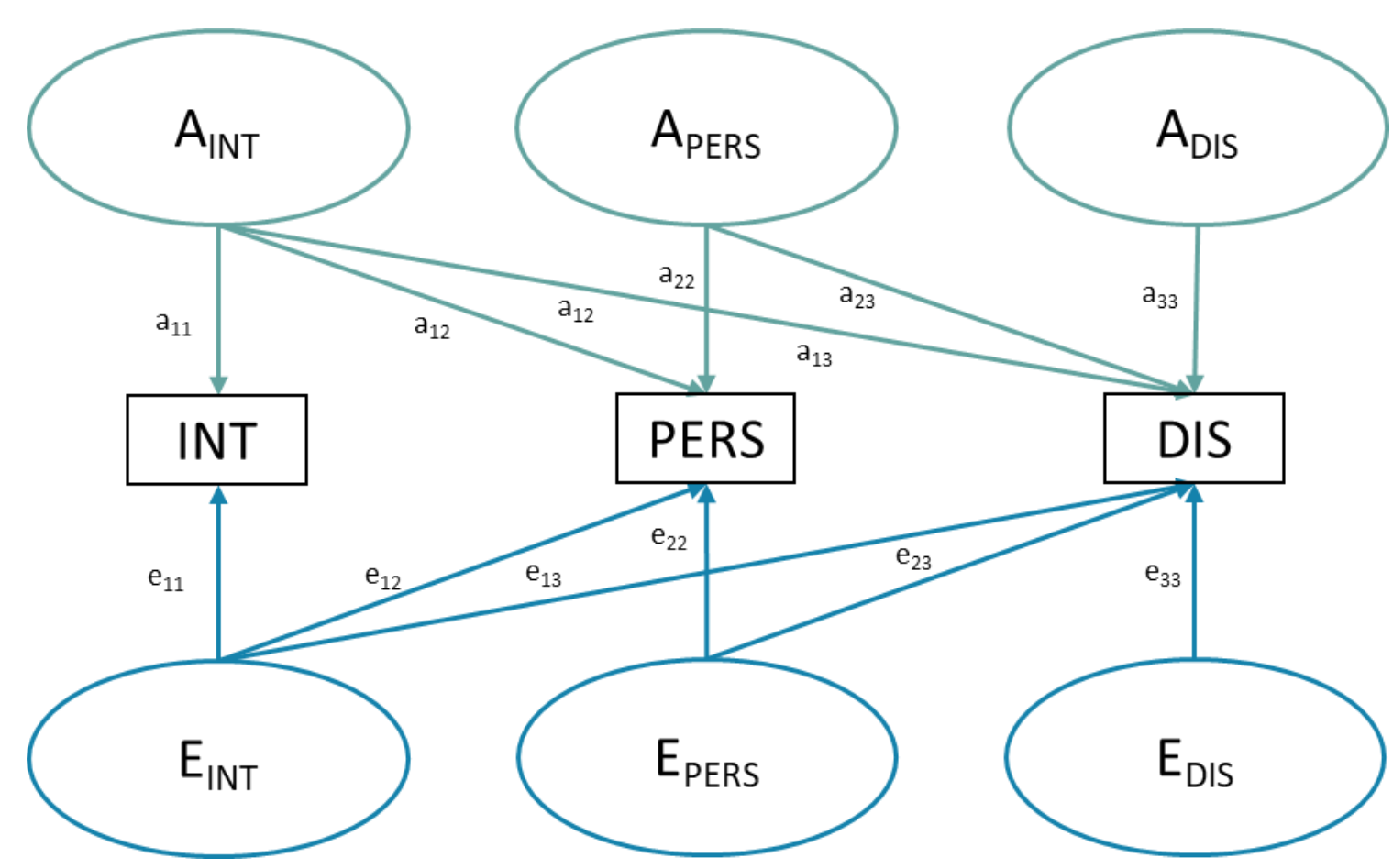

Note. a) Example bivariate Cholesky and b) example trivariate Cholesky. INT = broad internalizing dimension; PERS = personality dimension; DIS = individual internalizing disorder. 


\section{Figure 2}

Common Additive Genetic Influences between Big 5 Personality Dimensions and Internalizing

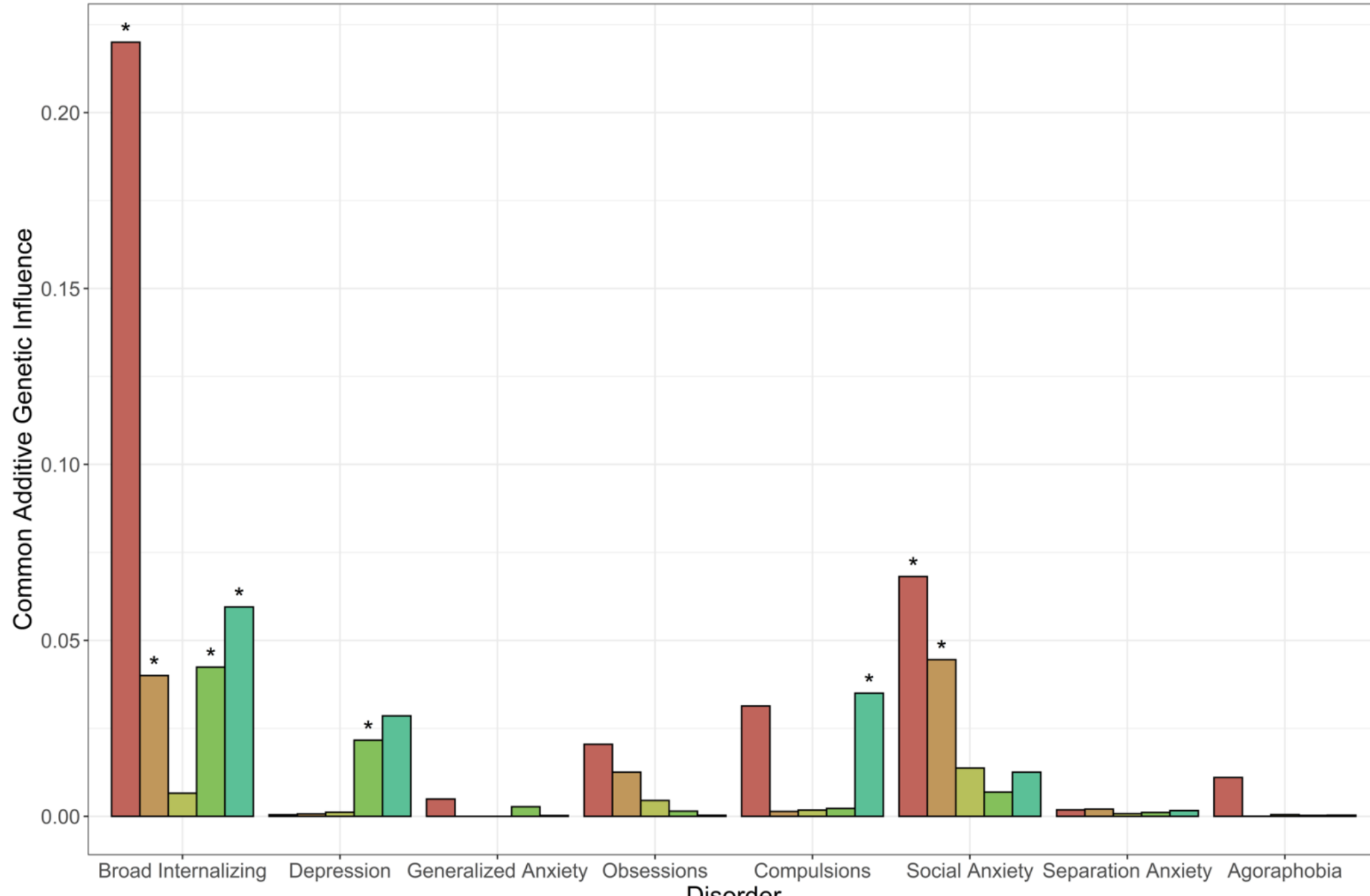

Big 5 Dimension

Neuroticism

Extraversion

Openness

Agreeableness

Conscientiousness

Disorder

Note. * denotes significance at $p<.05$ 


\section{Supplemental Material}

\section{Supplemental Table 1}

Summary of Univariate Quantitative Genetic Models

\begin{tabular}{|c|c|c|c|c|c|c|c|c|c|}
\hline \multicolumn{6}{|c|}{ Model Fit Statistics } & \multicolumn{4}{|c|}{ Parameter Estimates } \\
\hline Model & $\chi^{2}(\mathbf{d f})$ & BIC & TLI & RMSEA $(90 \%$ CI $)$ & SRMR & $\mathbf{a}^{2}$ & $c^{2} / d^{2}$ & $\mathbf{e}^{2}$ & $\mathbf{s}$ \\
\hline \multicolumn{10}{|c|}{ Internalizing Factor Scores } \\
\hline ACE & $15(5)$ & 4341 & .92 & $.07(.03, .11)$ & .31 & .73 & .00 & .27 & - \\
\hline $\mathrm{ACE}+\mathrm{s}$ & \multicolumn{9}{|c|}{ DID NOT CONVERGE } \\
\hline $\mathrm{ADE}$ & $18(5)$ & 4340 & .89 & $.08(.04, .12)$ & .31 & .63 & .11 & .26 & - \\
\hline $\mathrm{ADE}+\mathrm{s}$ & $14(4)$ & 4339 & .90 & $.08(.04, .12)$ & .28 & .83 & .00 & .21 & -.08 \\
\hline $\mathbf{A E}$ & $18(6)$ & 4334 & .92 & $.07(.03, .11)$ & .31 & .73 & - & .27 & - \\
\hline $\mathrm{AE}+\mathrm{s}$ & $17(5)$ & 4333 & .90 & $.08(.04, .12)$ & .28 & .83 & - & .21 & -.08 \\
\hline $\mathrm{CE}$ & $40(6)$ & 4416 & .78 & $.11(.08, .15)$ & .28 & - & .45 & .55 & - \\
\hline $\mathrm{CE}+\mathrm{s}$ & \multicolumn{9}{|c|}{ DID NOT CONVERGE } \\
\hline \multicolumn{10}{|l|}{ Depression } \\
\hline $\mathrm{ACE}$ & $5(5)$ & 208 & 1.00 & $.01(.00, .07)$ & .15 & .62 & .00 & .38 & - \\
\hline $\mathrm{ACE}+\mathrm{s}$ & \multicolumn{9}{|c|}{ DID NOT CONVERGE } \\
\hline $\mathrm{ADE}$ & $6(5)$ & 208 & .99 & $.02(.00, .07)$ & .15 & .47 & .16 & .37 & - \\
\hline $\mathrm{ADE}+\mathrm{s}$ & $5(4)$ & 212 & .99 & $.02(.00, .08)$ & .14 & .71 & .00 & .32 & -.06 \\
\hline $\mathbf{A E}$ & $7(6)$ & 202 & 1.00 & $.01(.00, .07)$ & .15 & .62 & - & .38 & - \\
\hline $\mathrm{AE}+\mathrm{s}$ & $6(5)$ & 205 & .99 & $.02(.00, .07)$ & .14 & .71 & - & .32 & -.06 \\
\hline $\mathrm{CE}$ & $13(6)$ & 243 & .94 & $.05(.01, .09)$ & .16 & - & .41 & .59 & - \\
\hline $\mathrm{CE}+\mathrm{s}$ & \multicolumn{9}{|c|}{ DID NOT CONVERGE } \\
\hline \multicolumn{10}{|c|}{ Generalized Anxiety } \\
\hline ACE & $6(5)$ & 1764 & 1.00 & $.03(.00, .08)$ & .13 & .72 & .00 & .28 & - \\
\hline $\mathrm{ACE}+\mathrm{s}$ & \multicolumn{9}{|c|}{ DID NOT CONVERGE } \\
\hline $\mathrm{ADE}$ & $7(5)$ & 1764 & .99 & $.03(.00, .08)$ & .13 & .62 & .09 & .28 & - \\
\hline $\mathrm{ADE}+\mathrm{s}$ & $5(4)$ & 1768 & .99 & $.03(.00, .08)$ & .11 & .78 & .00 & .25 & -.05 \\
\hline $\mathbf{A E}$ & $8(6)$ & 1757 & 1.00 & $.03(.00, .07)$ & .13 & .72 & - & .28 & - \\
\hline $\mathrm{AE}+\mathrm{s}$ & $7(5)$ & 1761 & .99 & $.03(.00, .08)$ & .11 & .78 & - & .25 & -.05 \\
\hline $\mathrm{CE}$ & $30(6)$ & 1830 & .93 & $.10(.06, .13)$ & .14 & & .47 & .53 & - \\
\hline $\mathrm{CE}+\mathrm{s}$ & $25(5)$ & 1837 & .93 & $.10(.06, .13)$ & .14 & & .70 & .42 & -.11 \\
\hline \multicolumn{10}{|l|}{ Obsessions } \\
\hline $\mathrm{ACE}$ & $6(5)$ & 5036 & .97 & $.02(.00, .07)$ & .39 & .61 & .00 & .40 & - \\
\hline $\mathrm{ACE}+\mathrm{s}$ & \multicolumn{9}{|c|}{ DID NOT CONVERGE } \\
\hline $\mathrm{ADE}$ & $6(5)$ & 5034 & .93 & $.03(.00, .08)$ & .39 & .42 & .21 & .37 & - \\
\hline $\mathrm{ADE}+\mathrm{s}$ & $5(4)$ & 5025 & .95 & $.02(.00, .08)$ & .34 & .80 & .00 & .25 & -.12 \\
\hline $\mathbf{A E}$ & $7(6)$ & 5029 & .97 & $.02(.00, .07)$ & .39 & .61 & - & .40 & - \\
\hline $\mathrm{AE}+\mathrm{s}$ & $6(5)$ & 5018 & .95 & $.02(.00, .07)$ & .34 & .80 & - & .25 & .12 \\
\hline $\mathrm{CE}$ & $9(6)$ & 5068 & .89 & $.03(.00, .08)$ & .36 & - & .33 & .67 & - \\
\hline $\mathrm{CE}+\mathrm{s}$ & $7(5)$ & 5075 & .89 & $.03(.00, .08)$ & .36 & - & .27 & .71 & .03 \\
\hline \multicolumn{10}{|l|}{ Compulsions } \\
\hline $\mathrm{ACE}$ & $6(5)$ & -1429 & .92 & $.02(.00, .08)$ & .37 & .26 & .08 & .65 & - \\
\hline $\mathrm{ACE}+\mathrm{s}$ & \multicolumn{9}{|c|}{ DID NOT CONVERGE } \\
\hline $\mathrm{ADE}$ & $6(5)$ & -1428 & .95 & $.02(.00, .07)$ & .37 & .37 & .00 & .63 & - \\
\hline
\end{tabular}




\begin{tabular}{|c|c|c|c|c|c|c|c|c|c|}
\hline $\mathrm{ADE}+\mathrm{s}$ & $7(4)$ & -1422 & .76 & $.04(.00, .09)$ & .36 & .48 & .00 & .55 & -.04 \\
\hline $\mathbf{A E}$ & $7(6)$ & -1435 & .95 & $.02(.00, .07)$ & .37 & .37 & - & .63 & - \\
\hline $\mathrm{AE}+\mathrm{S}$ & $8(5)$ & -1429 & .76 & $.04(.00, .09)$ & .36 & .48 & & .54 & -.04 \\
\hline $\mathrm{CE}$ & $6(6)$ & -1432 & .97 & $.01(.00, .07)$ & .36 & - & .25 & .75 & - \\
\hline $\mathrm{CE}+\mathrm{s}$ & \multicolumn{9}{|c|}{ DID NOT CONVERGE } \\
\hline \multicolumn{10}{|c|}{ Social Anxiety } \\
\hline ACE & $14(5)$ & 2147 & .77 & $.06(.03, .11)$ & .18 & .47 & .00 & .53 & - \\
\hline $\mathrm{ACE}+\mathrm{S}$ & \multicolumn{9}{|c|}{ DID NOT CONVERGE } \\
\hline $\mathrm{ADE}$ & $16(5)$ & 2140 & .71 & $.07(.04, .11)$ & .18 & .06 & .46 & .48 & - \\
\hline $\mathrm{ADE}+\mathrm{s}$ & $13(4)$ & 2137 & .73 & $.07(.03, .12)$ & .16 & .72 & .00 & .33 & -.13 \\
\hline $\mathbf{A E}$ & $17(6)$ & 2141 & .77 & $.06(.03, .10)$ & .18 & .47 & - & .53 & - \\
\hline $\mathrm{AE}+\mathrm{s}$ & $16(5)$ & 2131 & .73 & $.07(.03, .11)$ & .16 & .72 & - & .33 & -.13 \\
\hline $\mathrm{CE}$ & $23(6)$ & 2172 & .64 & $.08(.05, .12)$ & .19 & - & .26 & .74 & - \\
\hline $\mathrm{CE}+\mathrm{s}$ & \multicolumn{9}{|c|}{ DID NOT CONVERGE } \\
\hline \multicolumn{10}{|c|}{ Separation Anxiety } \\
\hline ACE & $3(5)$ & 729 & 1.00 & $.00(.00, .05)$ & .14 & .80 & .00 & .20 & - \\
\hline $\mathrm{ACE}+\mathrm{s}$ & \multicolumn{9}{|c|}{ DID NOT CONVERGE } \\
\hline $\mathrm{ADE}$ & $3(5)$ & 727 & 1.00 & $.00(.00, .06)$ & .14 & .63 & .17 & .20 & - \\
\hline $\mathrm{ADE}+\mathrm{s}$ & $2(4)$ & 730 & 1.00 & $.00(.00, .06)$ & .12 & .87 & .00 & .17 & -.06 \\
\hline $\mathbf{A E}$ & $4(6)$ & 722 & 1.00 & $.00(.00, .05)$ & .14 & .80 & - & .20 & - \\
\hline $\mathrm{AE}+\mathrm{s}$ & $3(5)$ & 723 & 1.00 & $.00(.00, .05)$ & .12 & .87 & - & .17 & -.06 \\
\hline $\mathrm{CE}$ & $21(6)$ & 859 & .86 & $.08(.04, .11)$ & .15 & - & .53 & .47 & - \\
\hline $\mathrm{CE}+\mathrm{s}$ & \multicolumn{9}{|c|}{ DID NOT CONVERGE } \\
\hline \multicolumn{10}{|c|}{ Agoraphobia } \\
\hline ACE & $18(5)$ & -596 & .79 & $.08(.04, .12)$ & .54 & .64 & .00 & .36 & - \\
\hline $\mathrm{ACE}+\mathrm{s}$ & \multicolumn{9}{|c|}{ DID NOT CONVERGE } \\
\hline $\mathrm{ADE}$ & $15(5)$ & -634 & .84 & $.07(.03, .11)$ & .54 & .00 & .71 & .29 & - \\
\hline $\mathrm{ADE}+\mathrm{s}$ & $9(4)$ & -681 & .90 & $.05(.00, .10)$ & .37 & .90 & .00 & .14 & -.24 \\
\hline $\mathrm{AE}$ & $21(6)$ & -603 & .79 & $.08(.04, .11)$ & .54 & .64 & - & .36 & \\
\hline $\mathbf{A E}+\mathbf{S}$ & $11(5)$ & -687 & .90 & $.05(.00, .10)$ & .37 & .91 & - & .14 & -.24 \\
\hline $\mathrm{CE}$ & $27(6)$ & -543 & .71 & $.09(.06, .13)$ & .48 & - & .23 & .77 & - \\
\hline $\mathrm{CE}+\mathrm{s}$ & \multicolumn{9}{|c|}{ DID NOT CONVERGE } \\
\hline
\end{tabular}

Note. Fit statistics and parameter estimates from best-fitting model are bolded. 


\section{Supplemental Table 2}

Model fit for Cholesky Decompositions of Internalizing, Little 5 Dimensions, and Depression

\begin{tabular}{|c|c|c|c|c|c|c|c|}
\hline & $\chi^{2}(\mathrm{df})$ & AIC & BIC & CFI & TLI & RMSEA (90\% CI) & SRMR \\
\hline \multicolumn{8}{|l|}{ Neuroticism } \\
\hline Fully Saturated & $79(42)$ & 5051 & 5108 & .93 & .95 & $.05(.03, .06)$ & .16 \\
\hline Neuroticism on $\mathrm{A}_{\mathrm{GEN}}$ dropped & $94(43)$ & 5084 & 5136 & .91 & .94 & $.05(.04, .07)$ & .18 \\
\hline Depression on APERS dropped & $80(43)$ & 5049 & 5101 & .93 & .95 & $.04(.03, .06)$ & .16 \\
\hline Neuroticism on $\mathrm{E}_{\mathrm{GEN}}$ dropped & $81(43)$ & 5050 & 5103 & .93 & .95 & $.05(.03, .06)$ & .16 \\
\hline Depression on EPERS dropped & $82(43)$ & 5053 & 5105 & .93 & .95 & $.05(.03, .06)$ & .16 \\
\hline \multicolumn{8}{|l|}{ Extraversion } \\
\hline Fully Saturated & $81(41)$ & 4907 & 4969 & .93 & .95 & $.05(.03, .06)$ & .17 \\
\hline Extraversion on $\mathrm{A}_{\mathrm{GEN}}$ dropped & $85(42)$ & 4912 & 4970 & .92 & .95 & $.05(.03, .06)$ & .18 \\
\hline Depression on APERS dropped & $82(42)$ & 4906 & 4962 & .93 & .95 & $.05(.03, .06)$ & .17 \\
\hline Extraversion on $\mathrm{E}_{\mathrm{GEN}}$ dropped & $83(42)$ & 4907 & 4965 & .93 & .95 & $.05(.03, .06)$ & .17 \\
\hline Depression on $E_{\text {PERS }}$ dropped & $86(42)$ & 4914 & 4972 & .92 & .94 & $.05(.03, .06)$ & .17 \\
\hline \multicolumn{8}{|l|}{ Openness } \\
\hline Fully Saturated & $78(42)$ & 4578 & 4635 & .94 & .96 & $.04(.03, .06)$ & .16 \\
\hline Openness on $\mathrm{A}_{\mathrm{GEN}}$ dropped & $80(43)$ & 4578 & 4631 & .94 & .96 & $.04(.03, .06)$ & .17 \\
\hline Depression on $A_{\text {PERS }}$ dropped & $79(43)$ & 4576 & 4629 & .94 & .96 & $.04(.03, .06)$ & .16 \\
\hline Openness on $\mathrm{E}_{\mathrm{GEN}}$ dropped & $80(43)$ & 4579 & 4632 & .94 & .96 & $.04(.03, .06)$ & .16 \\
\hline Depression on EPERS dropped & $79(43)$ & 4577 & 4630 & .94 & .96 & $.04(.03, .06)$ & .16 \\
\hline \multicolumn{8}{|l|}{ Agreeableness } \\
\hline Fully Saturated & $86(42)$ & 5035 & 5093 & .93 & .95 & $.05(.03, .06)$ & .17 \\
\hline Agreeableness on $\mathrm{A}_{\mathrm{GEN}}$ dropped & $91(43)$ & 5044 & 5096 & .92 & .94 & $.05(.04, .07)$ & .18 \\
\hline Depression on APERS dropped & $90(43)$ & 5040 & 5093 & .92 & .94 & $.05(.04, .06)$ & .17 \\
\hline Agreeableness on $\mathrm{E}_{\mathrm{GEN}}$ dropped & $87(43)$ & 5034 & 5086 & .92 & .95 & $.05(.03, .06)$ & .17 \\
\hline Depression on E $E_{\text {PERS }}$ dropped & $88(43)$ & 5035 & 5088 & .92 & .95 & $.05(.03, .06)$ & .17 \\
\hline \multicolumn{8}{|l|}{ Conscientiousness } \\
\hline Fully Saturated & $92(42)$ & 5346 & 5403 & .92 & .94 & $.05(.04, .07)$ & .17 \\
\hline Conscientiousness on $A_{\mathrm{GEN}}$ dropped & $96(43)$ & 5352 & 5405 & .91 & .94 & $.05(.04, .07)$ & .18 \\
\hline Depression on APERS dropped & $95(43)$ & 5349 & 5402 & .91 & .94 & $.05(.04, .07)$ & .18 \\
\hline Conscientiousness on $\mathrm{E}_{\mathrm{GEN}}$ dropped & $93(43)$ & 5345 & 5398 & .91 & .94 & $.05(.04, .07)$ & .18 \\
\hline Depression on EPERS dropped & $94(43)$ & 5349 & 5402 & .91 & .94 & $.05(.04, .07)$ & .18 \\
\hline
\end{tabular}




\section{Supplemental Table 3}

Model fit for Cholesky Decompositions of Internalizing, Little 5 Dimensions, and Generalized Anxiety

\begin{tabular}{|c|c|c|c|c|c|c|c|}
\hline & $\chi^{2}(\mathbf{d f})$ & AIC & BIC & CFI & TLI & RMSEA (90\% CI) & SRMR \\
\hline \multicolumn{8}{|l|}{ Neuroticism } \\
\hline Fully Saturated & $123(42)$ & 5349 & 5406 & 0.93 & 0.95 & $.07(.05, .08)$ & 0.16 \\
\hline Neuroticism on $\mathrm{A}_{\mathrm{GEN}}$ dropped & $139(43)$ & 5377 & 5430 & 0.92 & 0.94 & $.07(.06, .08)$ & 0.19 \\
\hline GAD on $A_{\text {PERS }}$ dropped & $125(43)$ & 5348 & 5401 & 0.93 & 0.95 & $.07(.05, .08)$ & 0.16 \\
\hline Neuroticism on $\mathrm{E}_{\mathrm{GEN}}$ dropped & $125(43)$ & 5347 & 5400 & 0.93 & 0.95 & $.07(.05, .08)$ & 0.17 \\
\hline GAD on $E_{\text {PERS }}$ dropped & $162(43)$ & 5434 & 5487 & 0.9 & 0.93 & $.08(.07, .09)$ & 0.19 \\
\hline \multicolumn{8}{|l|}{ Extraversion } \\
\hline Fully Saturated & $129(41)$ & 5207 & 5269 & 0.93 & 0.95 & $.07(.06, .08)$ & 0.17 \\
\hline Extraversion on $A_{\mathrm{GEN}}$ dropped & $133(42)$ & 5211 & 5268 & 0.93 & 0.95 & $.07(.06, .08)$ & 0.18 \\
\hline GAD on APERS dropped & $130(42)$ & 5205 & 5263 & 0.93 & 0.95 & $.07(.06, .08)$ & 0.17 \\
\hline Extraversion on $\mathrm{E}_{\mathrm{GEN}}$ dropped & $140(42)$ & 5206 & 5263 & 0.93 & 0.95 & $.07(.06, .08)$ & 0.17 \\
\hline GAD on EPERS dropped & $131(42)$ & 5207 & 5264 & 0.93 & 0.95 & $.07(.06, .08)$ & 0.17 \\
\hline \multicolumn{8}{|l|}{ Openness } \\
\hline Fully Saturated & $116(42)$ & 4865 & 4923 & 0.94 & 0.96 & $.06(.05, .08)$ & 0.16 \\
\hline Openness on $\mathrm{A}_{\mathrm{GEN}}$ dropped & $119(43)$ & 4865 & 4918 & 0.94 & 0.96 & $.06(.05, .08)$ & 0.16 \\
\hline GAD on $A_{\text {PERS }}$ dropped & $118(43)$ & 4863 & 4916 & 0.94 & 0.96 & $.06(.05, .08)$ & 0.16 \\
\hline Openness on $\mathrm{E}_{\mathrm{GEN}}$ dropped & $119(43)$ & 4866 & 4918 & 0.94 & 0.96 & $.06(.05, .08)$ & 0.16 \\
\hline GAD on $E_{\text {PERS }}$ dropped & $120(43)$ & 4867 & 4919 & 0.94 & 0.96 & $.06(.05, .08)$ & 0.16 \\
\hline \multicolumn{8}{|l|}{ Agreeableness } \\
\hline Fully Saturated & $130(42)$ & 5326 & 5384 & 0.93 & 0.95 & $.07(.06, .08)$ & 0.17 \\
\hline Agreeableness on $A_{\mathrm{GEN}}$ dropped & $137(43)$ & 5334 & 5387 & 0.93 & 0.95 & $.07(.06, .08)$ & 0.17 \\
\hline GAD on APERS dropped & $133(43)$ & 5327 & 5379 & 0.93 & 0.95 & $.07(.06, .08)$ & 0.17 \\
\hline Agreeableness on $\mathrm{E}_{\mathrm{GEN}}$ dropped & $132(43)$ & 5324 & 5377 & 0.93 & 0.95 & $.07(.06, .08)$ & 0.17 \\
\hline GAD on EPERS dropped & $132(43)$ & 5325 & 5377 & 0.93 & 0.95 & $.07(.06, .08)$ & 0.17 \\
\hline \multicolumn{8}{|l|}{ Conscientiousness } \\
\hline Fully Saturated & $133(42)$ & 5639 & 5696 & 0.93 & 0.95 & $.07(.06, .08)$ & 0.17 \\
\hline Conscientiousness on $\mathrm{A}_{\mathrm{GEN}}$ dropped & $140(43)$ & 5647 & 5700 & 0.92 & 0.95 & $.07(.06, .08)$ & 0.18 \\
\hline GAD on APERS dropped & $135(43)$ & 5637 & 5689 & 0.93 & 0.95 & $.07(.06, .08)$ & 0.17 \\
\hline Conscientiousness on $\mathrm{E}_{\mathrm{GEN}}$ dropped & $137(43)$ & 5641 & 5694 & 0.93 & 0.95 & $.07(.06, .08)$ & 0.17 \\
\hline GAD on $E_{\text {PERS }}$ dropped & $136(43)$ & 5641 & 5693 & 0.93 & 0.95 & $.07(.06, .08)$ & 0.17 \\
\hline
\end{tabular}




\section{Supplemental Table 4}

Model fit for Cholesky Decompositions of Internalizing, Little 5 Dimensions, and Obsessions

\begin{tabular}{|c|c|c|c|c|c|c|c|}
\hline & $\chi^{2}(\mathrm{df})$ & AIC & BIC & CFI & TLI & RMSEA $(90 \%$ CI $)$ & SRMR \\
\hline \multicolumn{8}{|l|}{ Neuroticism } \\
\hline Fully Saturated & $117(42)$ & 4133 & 4191 & .73 & .81 & $.06(.05, .08)$ & .32 \\
\hline Neuroticism on $A_{\mathrm{GEN}}$ dropped & $127(43)$ & 4160 & 4212 & .70 & .79 & $.06(.05, .08)$ & .33 \\
\hline Obsessions on APERS dropped & $119(43)$ & 4133 & 4186 & .73 & .81 & $.06(.05, .08)$ & .31 \\
\hline Neuroticism on $\mathrm{E}_{\mathrm{GEN}}$ dropped & $119(43)$ & 4132 & 4185 & .73 & .81 & $.06(.05, .08)$ & .32 \\
\hline Obsessions on $\mathrm{E}_{\text {PERS }}$ dropped & $118(43)$ & 4131 & 4184 & .73 & .81 & $.06(.05, .08)$ & .32 \\
\hline \multicolumn{8}{|l|}{ Extraversion } \\
\hline Fully Saturated & $120(41)$ & 3992 & 4054 & .72 & .80 & $.07(.05, .08)$ & .32 \\
\hline Extraversion on $A_{\mathrm{GEN}}$ dropped & $124(42)$ & 3994 & 4051 & .71 & .79 & $.07(.05, .08)$ & .32 \\
\hline Obsessions on ApERs dropped & $124(42)$ & 3993 & 4051 & .71 & .79 & $.07(.05, .08)$ & .32 \\
\hline Extraversion on $\mathrm{E}_{\mathrm{GEN}}$ dropped & $122(42)$ & 3990 & 4048 & .72 & .80 & $.07(.05, .08)$ & .32 \\
\hline Obsessions on EPERS dropped & $122(42)$ & 3990 & 4047 & .72 & .80 & $.07(.05, .08)$ & .32 \\
\hline \multicolumn{8}{|l|}{ Openness } \\
\hline Fully Saturated & $122(42)$ & 3655 & 3713 & .74 & .81 & $.07(.05, .08)$ & .32 \\
\hline Openness on $\mathrm{A}_{\mathrm{GEN}}$ dropped & $124(43)$ & 3655 & 3707 & .74 & .82 & $.07(.05, .08)$ & .32 \\
\hline Obsessions on A $A_{\text {PERS }}$ dropped & $124(43)$ & 3655 & 3707 & .74 & .82 & $.07(.05, .08)$ & .32 \\
\hline Openness on $\mathrm{E}_{\mathrm{GEN}}$ dropped & $124(43)$ & 3655 & 3708 & .74 & .82 & $.07(.05, .08)$ & .32 \\
\hline Obsessions on E $E_{\text {PERS }}$ dropped & $123(43)$ & 3653 & 3706 & .74 & .82 & $.07(.05, .08)$ & .32 \\
\hline \multicolumn{8}{|l|}{ Agreeableness } \\
\hline Fully Saturated & $127(42)$ & 4119 & 4176 & .72 & .80 & $.07(.05, .08)$ & .32 \\
\hline Agreeableness on $A_{\mathrm{GEN}}$ dropped & $133(43)$ & 4128 & 4181 & .71 & .79 & $.07(.06, .08)$ & .32 \\
\hline Obsessions on APERS dropped & $128(43)$ & 4117 & 4170 & .72 & .81 & $.07(.05, .08)$ & .32 \\
\hline Agreeableness on $\mathrm{E}_{\mathrm{GEN}}$ dropped & $129(43)$ & 4117 & 4170 & .72 & .8 & $.07(.05, .08)$ & .32 \\
\hline Obsessions on $E_{\text {PERS }}$ dropped & $128(43)$ & 4117 & 4170 & .72 & .81 & $.07(.05, .08)$ & .32 \\
\hline \multicolumn{8}{|l|}{ Conscientiousness } \\
\hline Fully Saturated & $126(42)$ & 4430 & 4487 & .71 & .80 & $.07(.05, .08)$ & .32 \\
\hline Conscientiousness on $\mathrm{A}_{\mathrm{GEN}}$ dropped & $132(43)$ & 4438 & 4490 & .70 & .79 & $.07(.06, .08)$ & .32 \\
\hline Obsessions on APERS dropped & $127(43)$ & 4428 & 4480 & .71 & .80 & $.07(.05, .08)$ & .32 \\
\hline Conscientiousness on $\mathrm{E}_{\mathrm{GEN}}$ dropped & $129(43)$ & 4431 & 4484 & .71 & .80 & $.07(.05, .08)$ & .32 \\
\hline Obsessions on EPERS dropped & $128(43)$ & 4428 & 4480 & .71 & .80 & $.07(.05, .08)$ & .32 \\
\hline
\end{tabular}




\section{Supplemental Table 5}

Model fit for Cholesky Decompositions of Internalizing, Little 5 Dimensions, and Compulsions

\begin{tabular}{|c|c|c|c|c|c|c|c|}
\hline & $\chi^{2}(\mathbf{d f})$ & AIC & BIC & CFI & TLI & RMSEA $(90 \%$ CI $)$ & SRMR \\
\hline \multicolumn{8}{|l|}{ Neuroticism } \\
\hline Fully Saturated & $66(42)$ & 3789 & 3846 & .94 & .96 & $.04(.02, .05)$ & .23 \\
\hline Neuroticism on $A_{\text {GEN }}$ dropped & $75(43)$ & 3815 & 3868 & .92 & .94 & $.04(.03, .06)$ & .24 \\
\hline Compulsions on APERS dropped & $68(43)$ & 3789 & 3841 & .94 & .96 & $.04(.02, .05)$ & .23 \\
\hline Neuroticism on $\mathrm{E}_{\mathrm{GEN}}$ dropped & $68(43)$ & 3787 & 3840 & .94 & .96 & $.04(.02, .05)$ & .23 \\
\hline Compulsions on $\mathrm{E}_{\mathrm{PERS}}$ dropped & $67(43)$ & 3787 & 3839 & .94 & .96 & $.04(.02, .05)$ & .23 \\
\hline \multicolumn{8}{|l|}{ Extraversion } \\
\hline Fully Saturated & $66(41)$ & 3652 & 3714 & .94 & .95 & $.04(.02, .05)$ & .23 \\
\hline Extraversion on $\mathrm{A}_{\mathrm{GEN}}$ dropped & $68(42)$ & 3654 & 3712 & .93 & .95 & $.04(.02, .05)$ & .23 \\
\hline Compulsions on APERS dropped & $67(42)$ & 3650 & 3707 & .94 & .95 & $.04(.02, .05)$ & .23 \\
\hline Extraversion on $\mathrm{E}_{\mathrm{GEN}}$ dropped & $67(42)$ & 3651 & 3708 & .94 & .95 & $.04(.02, .05)$ & .23 \\
\hline Compulsions on EPERS dropped & $67(42)$ & 3650 & 3707 & .94 & .95 & $.04(.02, .05)$ & .23 \\
\hline \multicolumn{8}{|l|}{ Openness } \\
\hline Fully Saturated & $63(42)$ & 3313 & 3370 & .95 & .96 & $.03(.01, .05)$ & .23 \\
\hline Openness on $\mathrm{A}_{\mathrm{GEN}}$ dropped & $65(43)$ & 3312 & 3365 & .95 & .96 & $.03(.02, .05)$ & .23 \\
\hline Compulsions on $A_{\text {PERS }}$ dropped & $65(43)$ & 3311 & 3364 & .95 & .96 & $.03(.01, .05)$ & .23 \\
\hline Openness on $\mathrm{E}_{\mathrm{GEN}}$ dropped & $65(43)$ & 3312 & 3365 & .95 & .96 & $.03(.02, .05)$ & .23 \\
\hline Compulsions on $E_{\text {PERS }}$ dropped & $65(43)$ & 3312 & 3365 & .95 & .96 & $.03(.02, .05)$ & .23 \\
\hline \multicolumn{8}{|l|}{ Agreeableness } \\
\hline Fully Saturated & $68(42)$ & 3773 & 3831 & .94 & .96 & $.04(.02, .05)$ & .23 \\
\hline Agreeableness on $\mathrm{A}_{\mathrm{GEN}}$ dropped & $72(43)$ & 3781 & 3824 & .93 & .95 & $.04(.02, .06)$ & .23 \\
\hline Compulsions on APERS dropped & $69(43)$ & 3772 & 3824 & .94 & .96 & $.04(.02, .05)$ & .23 \\
\hline Agreeableness on $\mathrm{E}_{\mathrm{GEN}}$ dropped & $69(43)$ & 3771 & 3824 & .94 & .96 & $.04(.02, .05)$ & .23 \\
\hline Compulsions on $\mathrm{E}_{\mathrm{PERS}}$ dropped & $69(43)$ & 3772 & 3825 & .94 & .96 & $.04(.02, .05)$ & .23 \\
\hline \multicolumn{8}{|l|}{ Conscientiousness } \\
\hline Fully Saturated & $67(42)$ & 4083 & 4141 & .94 & .96 & $.04(.02, .05)$ & .23 \\
\hline Conscientiousness on $\mathrm{A}_{\mathrm{GEN}}$ dropped & $70(43)$ & 4089 & 4142 & .93 & .95 & $.04(.02, .05)$ & .24 \\
\hline Compulsions on APERS dropped & $69(43)$ & 4085 & 4137 & .93 & .95 & $.04(.02, .05)$ & .23 \\
\hline Conscientiousness on $\mathrm{E}_{\mathrm{GEN}}$ dropped & $68(43)$ & 4083 & 4136 & .94 & .96 & $.04(.02, .05)$ & .23 \\
\hline Compulsions on EPERS dropped & $68(43)$ & 4083 & 4135 & .94 & .96 & $.04(.02, .05)$ & .23 \\
\hline
\end{tabular}




\section{Supplemental Table 6}

Model fit for Cholesky Decompositions of Internalizing, Little 5 Dimensions, and Social Anxiety

\begin{tabular}{|c|c|c|c|c|c|c|c|}
\hline & $\chi^{2}(\mathrm{df})$ & AIC & BIC & CFI & TLI & RMSEA $(90 \%$ CI $)$ & SRMR \\
\hline \multicolumn{8}{|l|}{ Neuroticism } \\
\hline Fully Saturated & $95(42)$ & 7274 & 7331 & .87 & .91 & $.05(.04, .07)$ & .17 \\
\hline Neuroticism on $\mathrm{A}_{\mathrm{GEN}}$ dropped & $110(43)$ & 7304 & 7356 & .83 & .88 & $.06(.05, .07)$ & .19 \\
\hline Social Anxiety on APERS dropped & $99(43)$ & 7280 & 7333 & .86 & .90 & $.05(.04, .07)$ & .17 \\
\hline Neuroticism on $\mathrm{E}_{\mathrm{GEN}}$ dropped & $96(43)$ & 7273 & 7326 & .87 & .91 & $.05(.04, .07)$ & .17 \\
\hline Social Anxiety on $E_{\text {PERS }}$ dropped & $95(43)$ & 7272 & 7325 & .87 & .91 & $.05(.04, .07)$ & .17 \\
\hline \multicolumn{8}{|l|}{ Extraversion } \\
\hline Fully Saturated & $98(41)$ & 7120 & 7183 & .86 & .90 & $.06(.04, .07)$ & .18 \\
\hline Extraversion on $\mathrm{A}_{\mathrm{GEN}}$ dropped & $102(42)$ & 7124 & 7181 & .85 & .90 & $.06(.04, .07)$ & .18 \\
\hline Social Anxiety on APERS dropped & $106(42)$ & 7134 & 7191 & .94 & .89 & $.06(.05, .07)$ & .18 \\
\hline Extraversion on $\mathrm{E}_{\mathrm{GEN}}$ dropped & $99(42)$ & 7119 & 7177 & .86 & .90 & $.06(.04, .07)$ & .18 \\
\hline Social Anxiety on EPERS dropped & $98(42)$ & 7119 & 7176 & .86 & .90 & $.06(.04, .07)$ & .18 \\
\hline \multicolumn{8}{|l|}{ Openness } \\
\hline Fully Saturated & $88(42)$ & 6794 & 6852 & .89 & .92 & $.05(.04, .06)$ & .17 \\
\hline Openness on $\mathrm{A}_{\mathrm{GEN}}$ dropped & $89(43)$ & 6794 & 6847 & .89 & .92 & $.05(.04, .06)$ & .17 \\
\hline Social Anxiety on APERS dropped & $90(43)$ & 6797 & 6849 & .88 & .92 & $.05(.04, .06)$ & .17 \\
\hline Openness on $\mathrm{E}_{\mathrm{GEN}}$ dropped & $90(43)$ & 6795 & 6847 & .89 & .92 & $.05(.04, .06)$ & .17 \\
\hline Social Anxiety on E EERS dropped & $89(43)$ & 6793 & 6846 & .89 & .92 & $.05(.04, .06)$ & .17 \\
\hline \multicolumn{8}{|l|}{ Agreeableness } \\
\hline Fully Saturated & $101(42)$ & 7266 & 7324 & .86 & .90 & $.06(.04, .07)$ & .17 \\
\hline Agreeableness on $\mathrm{A}_{\mathrm{GEN}}$ dropped & $108(43)$ & 7274 & 7327 & .85 & .89 & $.06(.05, .07)$ & .18 \\
\hline Social Anxiety on APERS dropped & $103(43)$ & 7266 & 7319 & .86 & .90 & $.06(.04, .07)$ & .18 \\
\hline Agreeableness on $\mathrm{E}_{\mathrm{GEN}}$ dropped & $103(43)$ & 7265 & 7317 & .86 & .90 & $.06(.04, .07)$ & .17 \\
\hline Social Anxiety on $E_{\text {PERS }}$ dropped & $103(43)$ & 7267 & 7319 & .86 & .90 & $.06(.04, .07)$ & .18 \\
\hline \multicolumn{8}{|l|}{ Conscientiousness } \\
\hline Fully Saturated & $100(42)$ & 7576 & 7633 & .86 & .90 & $.06(.04, .07)$ & .17 \\
\hline Conscientiousness on $\mathrm{A}_{\mathrm{GEN}}$ dropped & $106(43)$ & 7584 & 7637 & .84 & .89 & $.06(.04, .07)$ & .18 \\
\hline Social Anxiety on APERS dropped & $102(43)$ & 7576 & 7629 & .85 & .90 & $.06(.04, .07)$ & .17 \\
\hline Conscientiousness on $\mathrm{E}_{\mathrm{GEN}}$ dropped & $103(43)$ & 7578 & 7630 & .85 & .90 & $.06(.04, .07)$ & .17 \\
\hline Social Anxiety on EPERS $_{\text {dropped }}$ & $102(43)$ & 7577 & 7630 & .85 & .90 & $.06(.04, .07)$ & .17 \\
\hline
\end{tabular}




\section{Supplemental Table 7}

Model fit for Cholesky Decompositions of Internalizing, Little 5 Dimensions, and Separation Anxiety

\begin{tabular}{|c|c|c|c|c|c|c|c|}
\hline & $\chi^{2}(\mathrm{df})$ & AIC & BIC & CFI & TLI & RMSEA (90\% CI) & SRMR \\
\hline \multicolumn{8}{|l|}{ Neuroticism } \\
\hline Fully Saturated & $66(42)$ & 5359 & 5416 & .97 & .98 & $.03(.02, .05)$ & .16 \\
\hline Neuroticism on $A_{G E N}$ dropped & $77(43)$ & 5386 & 5439 & .95 & .96 & $.04(.03, .06)$ & .18 \\
\hline Separation Anxiety on APERS dropped & $66(43)$ & 5357 & 5410 & .97 & .98 & $.04(.02, .05)$ & .16 \\
\hline Neuroticism on $\mathrm{E}_{\mathrm{GEN}}$ dropped & $66(43)$ & 5358 & 5410 & .97 & .98 & $.04(.02, .05)$ & .16 \\
\hline Separation Anxiety on $\mathrm{E}_{\mathrm{PERS}}$ dropped & $67(43)$ & 5357 & 5410 & .97 & .98 & $.04(.02, .05)$ & .16 \\
\hline \multicolumn{8}{|l|}{ Extraversion } \\
\hline Fully Saturated & $63(41)$ & 5219 & 5281 & .97 & .98 & $.04(.02, .05)$ & .17 \\
\hline Extraversion on $A_{\text {GEN }}$ dropped & $66(42)$ & 5221 & 5278 & .96 & .98 & $.04(.02, .05)$ & .17 \\
\hline Separation Anxiety on APERS dropped & $64(42)$ & 5217 & 5275 & .97 & .98 & $.04(.02, .05)$ & .17 \\
\hline Extraversion on $\mathrm{E}_{\mathrm{GEN}}$ dropped & $64(42)$ & 5217 & 5274 & .97 & .98 & $.04(.02, .05)$ & .17 \\
\hline Separation Anxiety on EPERS dropped & $65(42)$ & 5219 & 5276 & .97 & .98 & $.04(.02, .05)$ & .17 \\
\hline \multicolumn{8}{|l|}{ Openness } \\
\hline Fully Saturated & $58(42)$ & 4880 & 4937 & .98 & .98 & $.03(.002, .05)$ & .16 \\
\hline Openness on $\mathrm{A}_{\mathrm{GEN}}$ dropped & $60(43)$ & 4880 & 4932 & .98 & .98 & $.03(.004, .05)$ & .16 \\
\hline Separation Anxiety on $A_{\text {PERS }}$ dropped & $59(43)$ & 4879 & 4931 & .98 & .98 & $.03(.002, .05)$ & .16 \\
\hline Openness on $\mathrm{E}_{\mathrm{GEN}}$ dropped & $60(43)$ & 4880 & 4933 & .98 & .98 & $.03(.005, .05)$ & .16 \\
\hline Separation Anxiety on E $E_{\text {PERS }}$ dropped & $59(43)$ & 4878 & 4931 & .98 & .98 & $.03(0, .05)$ & .16 \\
\hline \multicolumn{8}{|l|}{ Agreeableness } \\
\hline Fully Saturated & $64(42)$ & 5345 & 5402 & .97 & .98 & $.03(.02, .05)$ & .17 \\
\hline Agreeableness on $A_{\mathrm{GEN}}$ dropped & $69(43)$ & 5354 & 5406 & .96 & .97 & $.04(.02, .05)$ & .17 \\
\hline Separation Anxiety on APERS dropped & $65(43)$ & 5344 & 5396 & .97 & .98 & $.03(.02, .05)$ & .17 \\
\hline Agreeableness on $\mathrm{E}_{\mathrm{GEN}}$ dropped & $65(43)$ & 5343 & 5395 & .97 & .98 & $.03(.02, .05)$ & .17 \\
\hline Separation Anxiety on EPERS dropped & $65(43)$ & 5343 & 5395 & .97 & .98 & $.03(.02, .05)$ & .17 \\
\hline \multicolumn{8}{|l|}{ Conscientiousness } \\
\hline Fully Saturated & $61(42)$ & 5649 & 5707 & .97 & .98 & $.03(.01, .05)$ & .17 \\
\hline Conscientiousness on $\mathrm{A}_{\mathrm{GEN}}$ dropped & $67(43)$ & 5660 & 5713 & .96 & .98 & $.04(.02, .05)$ & .17 \\
\hline Separation Anxiety on APERS dropped & $62(43)$ & 5649 & 5702 & .97 & .98 & $.03(.01, .05)$ & .17 \\
\hline Conscientiousness on $\mathrm{E}_{\mathrm{GEN}}$ dropped & $65(43)$ & 5654 & 5706 & .97 & .98 & $.03(.01, .05)$ & .17 \\
\hline Separation Anxiety on EPERS dropped & $64(43)$ & 5652 & 5705 & .97 & .98 & $.03(.01, .05)$ & .17 \\
\hline
\end{tabular}




\section{Supplemental Table 8}

Model fit for Cholesky Decompositions of Internalizing, Little 5 Dimensions, and Agoraphobia

\begin{tabular}{|c|c|c|c|c|c|c|c|}
\hline & $\chi^{2}(\mathrm{df})$ & AIC & BIC & CFI & TLI & RMSEA $(90 \% \mathrm{CI})$ & SRMR \\
\hline \multicolumn{8}{|l|}{ Neuroticism } \\
\hline Fully Saturated & $114(42)$ & 3827 & 3884 & .94 & .96 & $.06(.05, .08)$ & .27 \\
\hline Neuroticism on $A_{\mathrm{GEN}}$ dropped & $125(43)$ & 3852 & 3905 & .93 & .95 & $.07(.05, .08)$ & .29 \\
\hline Agoraphobia on A AERS dropped & $116(43)$ & 3826 & 3879 & .94 & .96 & $.06(.05, .08)$ & .27 \\
\hline Neuroticism on $\mathrm{E}_{\mathrm{GEN}}$ dropped & $115(43)$ & 3825 & 3878 & .94 & .96 & $.06(.05, .08)$ & .27 \\
\hline Agoraphobia on $E_{\text {PERS }}$ dropped & $115(43)$ & 3825 & 3878 & .94 & .96 & $.06(.05, .08)$ & .27 \\
\hline \multicolumn{8}{|l|}{ Extraversion } \\
\hline Fully Saturated & $114(41)$ & 3689 & 3751 & .94 & .95 & $.06(.05, .08)$ & .27 \\
\hline Extraversion on $A_{G E N}$ dropped & $118(42)$ & 3693 & 3750 & .93 & .95 & $.06(.05, .08)$ & .28 \\
\hline Agoraphobia on APERS dropped & $116(42)$ & 3687 & 3745 & .94 & .95 & $.06(.05, .08)$ & .27 \\
\hline Extraversion on $\mathrm{E}_{\mathrm{GEN}}$ dropped & $116(42)$ & 3688 & 3745 & .94 & .95 & $.06(.05, .08)$ & .27 \\
\hline Agoraphobia on E EERS dropped & $116(42)$ & 3687 & 3745 & .94 & .95 & $.06(.05, .08)$ & .27 \\
\hline \multicolumn{8}{|l|}{ Openness } \\
\hline Fully Saturated & $109(42)$ & 3350 & 3407 & .94 & .96 & $.06(.05, .07)$ & .27 \\
\hline Openness on $\mathrm{A}_{\mathrm{GEN}}$ dropped & $112(43)$ & 3350 & 3402 & .94 & .96 & $.06(.05, .07)$ & .27 \\
\hline Agoraphobia on APERS dropped & $111(43)$ & 3348 & 3401 & .94 & .96 & $.06(.05, .07)$ & .27 \\
\hline Openness on $\mathrm{E}_{\mathrm{GEN}}$ dropped & $112(43)$ & 3351 & 3403 & .94 & .96 & $.06(.05, .07)$ & .27 \\
\hline Agoraphobia on $\mathrm{E}_{\mathrm{PERS}}$ dropped & $111(43)$ & 3348 & 3401 & .94 & .96 & $.06(.05, .07)$ & .27 \\
\hline \multicolumn{8}{|l|}{ Agreeableness } \\
\hline Fully Saturated & $118(42)$ & 3812 & 3870 & .94 & .96 & $.06(.05, .08)$ & .27 \\
\hline Agreeableness on $\mathrm{A}_{\mathrm{GEN}}$ dropped & $124(43)$ & 3820 & 3873 & .93 & .95 & $.07(.05, .08)$ & .28 \\
\hline Agoraphobia on APERS dropped & $120(43)$ & 3810 & 3863 & .94 & .96 & $.06(.05, .08)$ & .27 \\
\hline Agreeableness on $\mathrm{E}_{\mathrm{GEN}}$ dropped & $121(43)$ & 3810 & 3863 & .94 & .96 & $.06(.05, .08)$ & .27 \\
\hline Agoraphobia on $E_{\text {PERS }}$ dropped & $120(43)$ & 3811 & 3863 & .94 & .96 & $.06(.05, .08)$ & .27 \\
\hline \multicolumn{8}{|l|}{ Conscientiousness } \\
\hline Fully Saturated & $118(42)$ & 4120 & 4178 & .94 & .96 & $.06(.05, .08)$ & .27 \\
\hline Conscientiousness on $\mathrm{A}_{\mathrm{GEN}}$ dropped & $123(43)$ & 4128 & 4181 & .93 & .95 & $.07(.05, .08)$ & .28 \\
\hline Agoraphobia on A AERS dropped & $120(43)$ & 4118 & 4171 & .94 & .96 & $.06(.05, .08)$ & .27 \\
\hline Conscientiousness on $E_{\text {GEN }}$ dropped & $121(43)$ & 4122 & 4175 & .94 & .96 & $.06(.05, .08)$ & .27 \\
\hline Agoraphobia on EPERS dropped & $120(43)$ & 4119 & 4172 & .94 & .96 & $.06(.05, .08)$ & .27 \\
\hline
\end{tabular}

